Women's Empowerment and HIV Prevention in Rural Malawi

Berit C. Gerritzen

October 2012 Discussion Paper no. 2012-22 
Editor:

Publisher:

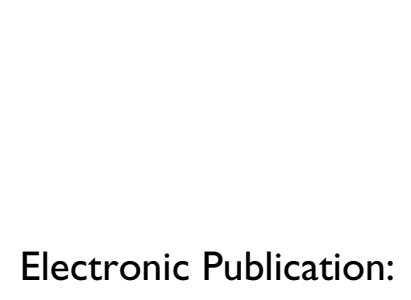

Martina Flockerzi

University of St. Gallen

School of Economics and Political Science

Department of Economics

Bodanstrasse 8

$\mathrm{CH}-9000$ St. Gallen

Phone +41712242325

Fax +41712243135

Email_seps@unisg.ch

School of Economics and Political Science

Department of Economics

University of St. Gallen

Bodanstrasse 8

$\mathrm{CH}-9000$ St. Gallen

Phone $\quad+41712242325$

Fax +41712243135

http://www.seps.unisg.ch 


\title{
Women's Empowerment and HIV Prevention in Rural Malawi ${ }^{1}$
}

\author{
Berit C. Gerritzen
}

Author's address:

Berit C. Gerritzen

Swiss Institute for International Economics and Applied

Economic Research SIAW-HSG

Bodanstrasse 8

$\mathrm{CH}-9000$ St. Gallen

Phone +41712243159

Fax $\quad+41712242298$

Email berit.gerritzen@unisg.ch

Website www.beritgerritzen.com

\footnotetext{
${ }^{1}$ I thank Bruno S. Frey, Oliver Gloede, Gebhard Kirchgässner, Hans-Peter Kohler, Michael Lechner, Giovanni Mellace, Katja Rost, and Jürgen Wolters, as well as participants at several seminars for helpful comments. Further, I am indebted to the Population Studies Center of the University of Pennsylvania for providing me with the MDICP data set, which is funded through NICHD grants R01HD053781 (Consequences of High Morbidity and Mortality in a Low-Income Country), R01HD044228 (AIDS/HIV Risk, Marriage and Sexual Relations in Malawi), R01HD/MH41713 (Gender, Conversational Networks and Dealing with STDs).
} 


\begin{abstract}
Condom use and communication among sexual partners are important strategies for HIV prevention. Using a panel data set of more than 1,200 married women in rural Malawi from 1998-2008, this paper shows that adequate HIV prevention strategies, i.e. condom use within marriage and HIV-related spousal communication, are more widely used as women's bargaining power increases. I focus on different dimensions of women's empowerment, namely personal and interpersonal empowerment. Among the proxies used for women's empowerment, own income, knowledge of other local languages and awareness of exit options from marriage are found to play a particularly important role in promoting adequate preventive behaviors. The main findings continue to hold after individual-specific fixed effects and time dummies are included in order to account for unobserved hetereogeneity and time trends.
\end{abstract}

\title{
Keywords
}

HIVIAIDS, Sub-Saharan Africa, gender, development, spousal communication, condom use within marriage.

\section{JEL Classification}

I14, O15, J16. 


\section{Introduction}

Condom use and communication among sexual partners are important strategies for HIV prevention (Noar et al., 2006). Using a panel data set of more than 1,200 married women in three regions in rural Malawi from 1998-2008, this paper shows that adequate HIV prevention strategies are more widely used as women's bargaining power increases. More specifically, the acceptance of condom use within marriage as well as HIV-related spousal communication become more prevalent as women become more empowered. I focus on different dimensions of women's empowerment, namely personal and interpersonal empowerment. Among the proxies used for women's personal empowerment, own income and knowledge of other (local) languages are found to play a crucial role in promoting adequate preventive behaviors. With respect to women's interpersonal empowerment, awareness of exit options from marriage is an important determinant of appropriate preventive measures. The main findings are robust to the inclusion of individual-specific fixed effects and time dummies in order to account for unobserved hetereogeneity. When analyzing the three regions of the survey separately, as well as when employing non-linear estimation methods, the results remain consistent with the main hypothesis, i.e. women's empowerment significantly promotes HIV prevention. Further, I analyze the relationship between HIV infection rates and different protection mechanisms. Spousal communication is associated with significantly lower levels of HIV prevalence, thereby suggesting that the chosen HIV prevention method is not only well-accepted from a cultural point of view, but also effective from a public health perspective. The results suggest that greater emphasis should be placed on women's empowerment in order to effectively combat the spread of AIDS, particularly in developing countries.

The data used stems from the Malawi Diffusion and Ideational Change Project, a joint initiative by the University of Pennsylvania and the Malawi College of Medicine, covering about 3,000 randomly selected male and female respondents in three distinctive districts of rural Malawi. I create a panel data set based on married women who participated in the first five waves of the MDICP (1998, 2001, 2004, 2006 and 2008) and use a linear probability model to estimate the effect of women's empowerment on the use and acceptance of HIV prevention methods. To the best of my knowledge, no analysis has been conducted using the full longitudinal MDICP sample. Since the same individuals were interviewed repeatedly in the survey, individual-specific fixed effects can be used in order to take into account time-invariant unobserved heterogeneity. Further, time dummies are included in order to control for time trends. Over the time period observed, several HIV prevention campaigns have been run in rural Malawi. In addition, HIV prevalence among the rural population has been rising over the past decade (UNAIDS, 2010, p. 18). One would therefore expect the level of awareness as well as knowledge with respect to HIV to be higher in 2008 than in 1998. Time dummies are meant to adequately capture this development.

When measuring women's empowerment, I employ a multidimensional approach focusing on both personal (e.g. education and economic empowerment) as well as interpersonal aspects (e.g. social status and outside options). I follow the empowerment definition of Gutiérrez et al. (2000, p. 583) where empowerment can be understood as "a process of increasing personal, interpersonal, or political power so that individuals can take action to improve their life situations". According to Gutiérrez et al. (2000), there are important feedback effects between individual HIV prevention efforts and structural factors, such as power dynamics between intimate partners or within the larger social context. These feedback effects will influence the effectiveness of individual prevention efforts. In the subsequent analysis, personal empowerment is measured by years of schooling, personal income during the last year, and knowledge of other (local) languages. Interpersonal empowerment is measured by dummy variables describing the respondents' attitude regarding acceptable reasons for a woman to leave her husband (e.g. violence and infidelity), the number of additional wives that her husband has and how old she was when she got married to him. In addition, a number of household and background characteristics such as family 
wealth, number of living children, and region of residence are being controlled for.

In the empirical analysis I first study the effect of women's empowerment on HIV-related spousal communication. The results show that own income plays a crucial role. The effect of own earnings is significant for all three income groups, but it is particularly important for medium-level incomes (both in terms of economic and statistical significance). Knowledge of other local languages also significantly promotes spousal communication, thereby reflecting a positive influence of larger circles of social interaction. With respect to interpersonal empowerment, women who consider violence and infidelity as appropriate reasons to leave, are significantly more likely to discuss HIV risk with their spouse. The same effect is found for those who would leave their spouse if he did not allow family planning. The number of additional wives is also associated with a higher likelihood of spousal communication, although this effect is not robust across all specifications.

Second, I investigate whether and how women's empowerment influences the acceptance of condom use within marriage. Again, women's earnings have a positive impact. However, a statistically significant effect can only be detected for women in the highest income group. In other words, only at higher levels of income is the increase in women's bargaining power that is due to generating own income sufficient in order to enable women to demand condom use from their husband. In terms of interpersonal empowerment, women who consider lack of financial support to be an adequate reason for a separation are significantly more likely to be in favor of condom use with their spouse. As expected, women who would leave their husband if he had HIV or did not allow family planning methods, are also more inclined to accept the use of condoms. This suggests that women who are aware of the danger of HIV and who know how to protect themselves will do so with their partner and will prefer to risk their relationship rather than to risk their life. The more co-wives a woman is living together with, the more open she is towards using condoms with her husband. In the case of concurrent partnerships, i.e. wives and co-wives living on the same compound, the threat of infection is probably much more real and direct, which will then lead to increased prevention efforts. When analyzing the determinants of condom use, it also has to be kept in mind that one could easily think of other factors rendering condom use in the context of marriage not to be the preferred option. For example, couples might decide not to use condoms for cultural reasons or because they desire to have children.

The results are robust to changing the estimation method from a linear to a non-linear specification, namely random effects logit and conditional fixed effects logit with bootstrapped standard errors. When performing the analysis for the three regions separately, the effect of women's empowerment differs across regions, particularly with respect to education and own earnings which is mainly because the level of education and income is higher in the North than in the South of Malawi. Thus, regional differences should be taken into account when designing empowerment programs.

In order to assess the effectiveness of the two HIV prevention strategies studied in this analysis, I regress HIV prevalence among the MDICP survey population on lagged values of variables measuring acceptance of condom use, HIV-related spousal communication as well as eight other protection methods. HIV-relevant spousal communication is significantly associated with lower HIV risk, whereas the results with respect to the acceptance of condom use within marriage are inconclusive. Even though there are no grounds on which the effectiveness of condoms in preventing HIV infections can be challenged in general, it remains questionable to expect a risk-reducing effect of condom use in this particular setting: The MDICP data studies married women who live in a traditional society that values many children, but associates condom use with infidelity (Zulu and Chepngeno, 2003, p. 274). In other words, from a public health perspective condoms might be the correct answer, but from a socio-cultural perspective, they are not. Unless perceptions and attitudes change, we should not be surprised to observe insignificant results with respect to the effect of condom use on HIV prevalence rates.

My study relates to two streams of literature on the relationship between women's empowerment and 
HIV prevention strategies. Besides the quantitative analyses discussed in more detail in the following, there are a range of studies that rely on qualitative methods such as semi-structured interviews (Schatz, 2005; Zulu and Chepngeno, 2003). The first stream of literature uses cross-sectional data from SubSaharan Africa in order to analyze the association between various dimensions of women's empowerment and HIV protection. Greig and Koopman (2003) use data from Botswana to show that condom use among sexually active women is positively associated with women's economic independence and negotiating power. Zulu and Chepngeno (2003) analyze the determinants of HIV-related spousal communication among participants of the Malawi Diffusion and Ideational Change Project and find that women with greater program exposure and informal social contacts are more likely to talk with their spouse about the risk of HIV. In a sample of 921 couples from Kigali (Rwanda), Van der Straten et al. (1998) find sexual coercion and physical violence in intimate relationships to be associated with larger HIV prevalence. I extend this literature by using panel data and by including individual-specific fixed effects and time dummies. This allows me to control for time-invariant unobserved heterogeneity and time trends in a way which is not possible in cross-sectional analysis. In other words, I can avoid omitted variable bias that might be due to unobservable factors such as socio-cultural norms that are likely to affect protection behavior.

The second stream of literature focuses on the identification of a causal relationship between economic empowerment of women and HIV prevention. Orfei (2010) provides an attempt to establish a causal relationship between low female bargaining power and high-risk male sexual behavior: using data from West Africa, the author studies the effect of exogenous variation in female empowerment (as measured by shocks to kin support due to death of one of her siblings) on male extramarital sexual behavior. His results suggest that a decrease in a woman's bargaining power following from the shock to kin support is associated with a significant increase in the likelihood that her husband is engaging in extramarital affairs. Another approach to avoid simultaneity and omitted variable bias in the context of HIV prevention is provided by Pronyk et al. (2008). Based on a cluster-randomized trial, the authors assess the effect of a combined microfinance and training intervention among young female participants in rural South Africa. Two years after the intervention, participants were significantly less likely to engage in HIV risk behavior (e.g. unprotected intercourse with a nonspousal partner) than the control group. Both of the aforementioned papers successfully identify a causal relationship between economic empowerment of women and HIV prevention. My analysis contributes to this literature by employing a multidimensional definition of women's empowerment that is not restricted to the economic dimension. To sum it up it can be said that my paper adds to the existing literature by combining the advantages of a panel data setting, i.e. the possibility to control for both time-invariant unobserved heterogeneity as well as time trends, with a multidimensional definition of women's empowerment, i.e. a definition that goes beyond economic empowerment and takes into account both personal as well as interpersonal aspects of empowerment.

The paper is organized as follows: Section 2 presents theoretical considerations related to HIV prevention and women's empowerment. Information on the data together with descriptive statistics is provided in Section 3. Section 4 explains the methodology as well as the main results. Validation and robustness testing is carried out in Section 5. Section 6 presents the main conclusions, policy recommendations as well as avenues for further research.

\section{Theoretical Considerations}

This chapter contains theoretical considerations relating to the analysis of HIV prevention in a rational choice framework. Further, I explain the choice of the two dependent variables and provide an introduction to the multidimensional definition of women's empowerment that is employed in the empirical analysis. 


\subsection{Analyzing HIV Prevention in a Rational Choice Framework}

For biological reasons, women face a greater risk of heterosexual transmission of HIV (Philipson and Posner, 1993, p. 76; Türmen, 2003, pp. 412-420). All other things being equal, women should therefore have an even higher incentive to use adequate HIV protection than men. However, particularly in developing countries, pronounced gender-specific differences can be observed with respect to both prevention as well as access to treatment of HIV (WHO, 2009, pp. xi-xii). Prima facie, the failure to use protection against a deadly disease seems irrational: HIV is a fatal, but avoidable illness and adequate protection is neither difficult to use nor very expensive. One would therefore expect the threat of dying from an HIV infection to result in a substantial incentive for using condoms. However, this does not need to be the case: Philipson and Posner (1993, pp. 31-51) analyze condom use in a rational choice framework and show that whether individuals use protection or not is determined by cost-utility considerations rather than merely by irrational behavior. The decision to use condoms is made under uncertainty, both with respect to one's own and the partner's serostatus as well as regarding the actual transmission probability of HIV. The authors argue that people derive more utility from unprotected sex due to the discomfort associated with using condoms. In this setting, safe sex will only be preferred if the expected costs associated with an HIV infection exceed the utility gain from risky sex.

Following this line of thinking, being a member of a culture where condom use is not well accepted in the context of marriage would then further add to the cost of condom use. In rural African societies, for example, condoms are strongly associated with infidelity and are therefore not typically considered as a prevention method that one would use with a spouse (Reniers, 2008; Zulu and Chepngeno, 2003, p. 274). Furthermore, in the absence of social security provisions, having many children can be important in order to ensure financial well-being in old age. Taken together, these cultural factors increase the costs associated with condom use. If this additional cost is not outweighed by the expected utility of avoiding an HIV infection, it might be rational for an individual not to use condoms. The same argument also holds for other HIV prevention methods: in a traditional society, a wife who wants to discuss adequate HIV prevention strategies with her husband might fall short of society's expectations. In other words, HIV prevention can be seen as causing disutility if it is not in line with socio-cultural expectations of what is considered to be adequate behavior. Therefore, women's empowerment is an important strategy in the fight against HIV if it manages to successfully re-shape traditional gender roles so that they accomodate adequate HIV prevention methods. ${ }^{1}$

Despite the many restrictions and limitations that women face in rural Malawi, they still have agency. Similarly to Reniers (2008), Schatz (2005), as well as Wojcicki and Malala (2001), I focus on women's agency and their capacity to act rather than on the structures and factors that limit their opportunities and that might result in helplessness. In other words, I study behavioral responses to HIV risk that women have instead of merely looking at factors that are beyond the individual's control such as e.g. faithfulness of the partner, or for women, the enforcement of condom use. Among the most common protection strategies in rural Malawi we find fidelity and spousal communication. According to Zulu and Chepngeno (2003), a woman who talks with her husband about the danger of HIV will mainly do so because she is worried that his behavior is putting both of them at risk of getting infected with the virus. Thus, the intention behind spousal communication is to increase awareness about the fact that spouses' fates are joined, that if one is infected with HIV, the other is likely to become infected as well (2003, pp. 262-269). These discussions often involve mentioning the future of their children and the danger of them having to grow up as orphans. Schatz (2005, pp. 483-489) and Zulu and Chepngeno (2003, pp.

\footnotetext{
${ }^{1}$ The importance of gender stereotypes and female role models in the context of economic and societal development has also been shown by Beaman et al. $(2009 ; 2012)$. Using evidence from the introduction of gender quotas in local politics in India, the authors analyze the effects of this policy measure on both adolescent girls' career aspirations as well as on gender bias in society in general.
} 
254-260) analyze semi-structured interviews that were conducted in the course of the Malawi Diffusion and Ideational Change Project and show that wives who are worried about their husband's infidelities will choose to sit him down and discuss the threat of HIV/AIDS. Many of the interviewed women stated that even if such discussions might not be sufficient to stop their husband from engaging in extra-marital affairs, at least they hope that after the conversation he would use condoms with other partners. In this regard, it also has to be taken into account that due to the widespread prevalence of polygamy in rural Malawi, concurrent partnerships are to a certain degree accepted and expected (Reniers and Tfaily, 2008, p. 1816; Zulu and Chepngeno, 2003). For the reasons just described, my analysis will focus on the determinants of two HIV prevention strategies, i.e. HIV-related spousal communication and acceptance of condom use within marriage.

\subsection{Towards a Multidimensional Definition of Women's Empowerment}

There are important feedback effects between individual HIV prevention efforts and structural factors, such as power dynamics between sexual partners or within the larger social context. Gutiérrez et al. (2000, pp. 583-590) study the HIV risk of female adolescents in the U.S. and explain how these feedback effects influence the effectiveness of individual HIV prevention efforts and why female bargaining power plays such an important role in the context of HIV prevention. According to the authors, empowerment can be understood as "a process of increasing personal, interpersonal, or political power so that individuals can take action to improve their life situations". Personal power can be described as "experiencing oneself as an effective and capable person". In the context of HIV prevention this implies that women understand the "ways in which they can take charge of their own health status through engaging in safer sex behaviors" (Gutiérrez et al., 2000, p. 586). In other words, an empowered woman would realize that her HIV status is not determined by fate or by others, but rather something that lies within her own hands. Factors that promote women's awareness about their agency with respect to HIV prevention are e.g. education and own income. ${ }^{2}$

Interpersonal power, on the other hand, involves "the ability to influence others with social power" that is derived from e.g. one's social status or role, interpersonal skills or credibility. Some of these bases of power will be ascriptive and based on factors such as race or class, whereas other bases of power can be developed by e.g. attaining social skills or new social positions (French and Raven, 1968). With respect to HIV prevention, interpersonal power will be influenced by one's social skills to negotiate relationships with significant others or by one's position - in society in general as well as in the context of an intimate relationship (Gutiérrez et al., 2000, p. 583 ff.). Women who enjoy a higher social status will feel more comfortable in demanding the use of adequate HIV protection from their partner. Partly, this confidence might stem from the awareness of options outside marriage: evidently, knowing that she has other means to finance her life (e.g. own income or a family to fall back on) will cause a woman to behave differently than if she was completely dependent on her husband. ${ }^{3}$ Therefore, interpersonal empowerment reflects both a woman's bargaining power within the relationship as well as her outside options.

The aforementioned theoretical considerations lead to two central hypotheses which shall be tested in the course of the paper:

\footnotetext{
${ }^{2}$ A theoretical description of the nexus between women's economic empowerment and HIV prevention is also given by Kim et al. (2008). For a concise review of the literature on the effect of women's empowerment on economic development in general, see Duflo (2011).

${ }^{3}$ The explanations above reflect a complementary understanding of spousal communication and women's outside options. One could also interprete communication and outside options as substitutes, thereby following Hirschman's (1970) model of exit, voice and loyalty. In Hirschman's $(1970,1995)$ terminology, there are three options to respond to a decline in the quality of economic and political organizations, namely one can give up support altogether (exit), express dissatisfaction (voice), or wait for an improvement (loyalty). Psychological literature by e.g. Rusbult and Zembrodt (1983) and Rusbult et al. (1982, pp. 1231-1235) has adapted the dimensions of exit, voice and loyalty to intimate relationships and furthermore extended Hirschman's model by a so-called neglect category.
} 
- H1: As women become more empowered, the probability for HIV-related spousal communication increases.

- H2: An increase in women's empowerment promotes the acceptance of condom use within marriage.

Following from the first two hypotheses is H3:

- H3: More widespread acceptance of adequate HIV prevention methods is associated with a decrease in HIV prevalence.

Hypotheses H1 and H2 are assessed in Chapter 4.1 (Determinants of Spousal Communication) and 4.2 (Determinants of Acceptance of Condom Use), respectively. Hypothesis H3 is adressed in Chapter 5.3 (Effectiveness of HIV Prevention Strategies).

\section{Data and Descriptive Statistics}

The data used stems from the Malawi Diffusion and Ideational Change Project (MDICP), an ongoing longitudinal survey covering about 3,000 randomly selected male and female respondents in three distinctive districts of rural Malawi: Rumphi district is located in the Northern region, Mchinji district in the Central region, and Balaka district in the Southern Region of the country. The MDICP is a joint project by the University of Pennsylvania and the Malawi College of Medicine that has been conducted in six waves since 1998. The aim of the MDICP survey is to examine the role of social interactions in changing demographic attitudes and behavior, e.g. with respect to the acceptance of modern contraceptive methods, smaller family size and strategies of protection against HIV/AIDS. In my analysis, I focus on female, married respondents who have been interviewed in the first five waves of the MDICP (1998, $2001,2004,2006$, and 2008, respectively). ${ }^{4}$

Due to differences in gender roles in the three regions, the MDICP data is well-fit to for the purpose of studying the effects of women's empowerment: In the Northern region, both residence and inheritance follow a patrilineal pattern, i.e. after marriage, the wife is expected to leave her hometown and move to her husband's family's compound and inheritance is traced through male family members only. The Southern region, on the other hand, has a longstanding tradition of matrilinearity. In the Central region, matrilinearity is less rigid than in the South, in particular residence can be both matrilocal or patrilocal. In terms of ethnicity and religion, the districts in themselves are rather homogenous: In the North, the Tumbuka are the dominant ethnicity and the majority of the Northern population is Protestant. The Central Region is mainly populated by Chewa who are with almost equal proportions Catholics and Protestants. The Southern Region is inhabited by Lomwe and Yao and has the highest proportion of Moslems (Watkins et al., 2003, p. 6; Helleringer and Kohler, 2005, pp. 267-271).

Descriptive statistics for all variables included in the analysis are given in Table $1 .{ }^{5}$ Detailed variable descriptions and descriptive statistics by region and year, respectively, can be found in the appendix. An overview on sample composition over time is also provided in the appendix.

\footnotetext{
${ }^{4}$ For a more detailled description of the MDICP data and sampling strategy, refer to Watkins et al. (2003), Thornton (2008, pp. 1831-1835), as well as the MDICP homepage (http://www.malawi.pop.upenn.edu/Level\%203/Malawi/docs/Sampling1.pdf).

${ }^{5}$ Apparent inconsistencies have been cleaned in the data and outliers have been dropped. For details, refer to Table 10 in the appendix (Variable descriptions). Estimating the models including outliers does not qualitatively change the findings. Results are available on request.
} 
Table 1: Descriptive statistics

\begin{tabular}{lccccc}
\hline Variable & Obs & Mean & Std. Dev. & Min & Max \\
\hline HIV prevalence and protection & strategies & & & \\
HIV & 2328 & 0.0623 & 0.2417 & 0 & 1 \\
spousal communication & 5320 & 0.8333 & 0.3728 & 0 & 1 \\
condom use w spouse & 5067 & 0.3000 & 0.4583 & 0 & 1 \\
\hline Empowerment (personal) & & & & & \\
education & 5857 & 3.6194 & 3.0087 & 0 & 13 \\
earnings & 5392 & 12791.09 & 34770.05 & 0 & 672000 \\
no earnings & 5392 & 0.1641 & 0.3704 & 0 & 1 \\
low earnings & 5392 & 0.2589 & 0.4381 & 0 & 1 \\
medium earnings & 5392 & 0.2865 & 0.4522 & 0 & 1 \\
high earnings & 5392 & 0.2904 & 0.4540 & 0 & 1 \\
language & 5790 & 0.6831 & 0.4653 & 0 & 1 \\
\hline Empowerment (interpersonal) & & & & \\
no financial support & 5135 & 0.3720 & 0.4834 & 0 & 1 \\
violence & 5137 & 0.7448 & 0.4360 & 0 & 1 \\
infidelity & 5134 & 0.7711 & 0.4201 & 0 & 1 \\
HIV infected & 5111 & 0.2356 & 0.4244 & 0 & 1 \\
no family planning & 5092 & 0.2425 & 0.4287 & 0 & 1 \\
polygamy & 5074 & 0.2730 & 0.4455 & 0 & 1 \\
number of wives & 5074 & 0.3569 & 0.7077 & 0 & 8 \\
age at marriage & 5152 & 20.1299 & 7.2701 & 12 & 69 \\
\hline Household and background characteristics & & & \\
relative wealth & 5079 & 2.6633 & 0.8380 & 1 & 5 \\
children & 5209 & 4.1102 & 2.1590 & 0 & 11 \\
number of marriages & 4944 & 1.4385 & 0.7444 & 1 & 7 \\
AIDS victims & 4973 & 11.3829 & 9.6273 & 0 & 100 \\
age & 5852 & 35.6032 & 11.8197 & 12 & 92 \\
central & 5858 & 0.3605 & 0.4802 & 0 & 1 \\
north & 5858 & 0.3132 & 0.4639 & 0 & 1 \\
south & 5858 & 0.3262 & 0.4689 & 0 & 1 \\
\hline & & & & & \\
\hline
\end{tabular}

\subsection{HIV Prevalence and Protection Strategies}

In 2004, 2006, and 2008, free HIV tests were offered to survey participants. The results of these tests are given in Table 1, indicating that $6.2 \%$ of the female MDICP survey participants are HIV-positive. HIV prevalence is highest for the sample population in the Southern region (9.6\%) and somewhat lower in the North (4.4\%) and in the Central region (4.8\%). HIV prevalence among women in the MDICP data is lower than the national average of $13 \%$ (12.9\%) that was found by the 2004 (2010) Malawi Demographic and Health Survey DHS. ${ }^{6}$ This difference is mainly due to the fact that urban areas, which tend to have higher infection rates, were excluded from the MDICP. However, the HIV rates in the MDICP data are comparable to the prevalence rate that was found among the rural population in the DHS (Thornton, 2008, p. 1832).

The main focus of this analysis is the impact of women's empowerment on HIV prevention strategies. The first dependent variable is spousal communication about HIV, a dummy variable that is 1 if the respondent indicates that she has talked with her current husband about the risk of HIV. The second dependent variable measures acceptance of condom use within marriage, i.e. the answer to the question "Do you think it is acceptable to use a condom with a spouse to protect against HIV/AIDS?". Needless to say, condom use is probably the most effective way of protection against HIV. Nevertheless, an alternative

\footnotetext{
${ }^{6}$ The Malawi Demographic and Health Survey DHS is a nationally representative study based on interviews with over 23,000 women. See also http://measuredhs.com/pubs/pdf/HF34/HF34.pdf and http://measuredhs.com/pubs/pdf/HF7/Malawi_HIV_factsheet.pdf.
} 
mode of HIV prevention has been included as due to socio-cultural reasons, using condoms with "risky" partners is often not an option. This is partly because in rural African societies having many children is desirable, but also because the use of condoms is associated with infidelity and therefore not well accepted within the context of marriage (Reniers, 2008). Fidelity and spousal communication have been shown to be more prevalent protection strategies than condom use (Zulu and Chepngeno, 2003). This also seems to hold for the MDICP sample, where $83.3 \%$ of the respondents indicate that they have discussed HIV with their spouse, but only $30 \%$ consider it acceptable to use condoms within marriage. Although acceptance of condom use has increased over time, remarkable regional differences remain as acceptance rates in the South are around $40 \%$, compared to $25 \%$ in the other two regions. Due to higher HIV rates in the South, awareness of the risk of becoming infected might be higher, thereby increasing acceptance of condom use in the context of marriage. Other risk reduction strategies involve the selection of low risk marriage partners and the divorce of spouses that are suspected to be infected with the HIV virus (Reniers, 2008).

\subsection{Empowerment (Personal and Interpersonal)}

The set of regressors includes a number of variables reflecting female bargaining power and empowerment (Gutiérrez et al., 2000). The measures of personal empowerment that are used in the following are years of schooling, personal income during the last year, and language skills. The average level of education among survey participants is very low (3.6 years), and so are average earnings (12'792 Malawi Kwacha correspond to approximately 50 USD). In the regression analysis, personal income will be described by dummy variables indicating whether a woman has no, low, medium or high personal income in comparison to the other survey participants in the respective year. The language variable takes the value 1 if the respondent speaks more than one language, which is the case for $68.3 \%$ of the sample; typically this would be another local language besides the one from her own tribe, as less than $5 \%$ of the MDICP population speak English. Language skills reflect a respondent's ability to communicate with people from other ethnicities, thereby making them less dependent on others for their communication needs and at the same time enlarging their circle of social interaction. The importance of social interaction as a "vector of change in the face of the HIV/AIDS epidemic" has been shown by e.g. Helleringer and Kohler (2005). Using the MDICP data, the authors find that social interaction increases both HIV awareness as well as the use of adequate prevention mechanisms and that this effect is particularly important for women.

In order to measure interpersonal power, several variables are available in the MDICP data. ${ }^{7}$ Five dummy variables describe respondents' attitude regarding acceptable reasons for a woman to leave her husband. These are: lack of financial support for her and the children, violence, infidelity, HIV infection of the spouse, and refusal to allow methods of family planning. Whereas intimate partner violence and infidelity are widely accepted as justifying a divorce, less than $25 \%$ of the respondents consider it to be appropriate to end the relationship because the husband has HIV or does not support family planning. Not surprisingly, women in the South, where HIV prevalence rates are much higher, are far more likely to approve of the two latter reasons for a divorce. $69 \%$ of the respondents in the North find it appropriate to leave an unfaithful husband, compared to over $80 \%$ in the other two regions. The greater tolerance for adultery in the North could be linked to the fact that polygamy is more prevalent in this region: $33.8 \%$ of the women in the North live in a polygamous relationship, compared to $22.7 \%$ and $25.9 \%$ in the Central and Southern region (see also Reniers and Tfaily, 2008, p. 1816).

A woman's position - both in the context of the intimate relationship with her spouse as well as in the household in general - is described by the number of additional wives that her current husband

\footnotetext{
${ }^{7}$ Gutiérrez et al.'s (2000) definition also includes political empowerment, described as "the ability to influence the allocation of resources in an orgnaization or community through formal or informal means" (2000, p. 586). Due to data restrictions, the political component of empowerment is not included in the subsequent analysis. The MDICP data contains a variable indicating the number of political meetings that respondents have attended during the past year. However, since this variable is not available for all waves, including it would drastically reduce the number of available observations.
} 
has besides her and how old she was when she got married to him. $27.3 \%$ of the women in the survey population are living in a polygamous relationship. However, the average number of additional wives is 0.36 , thereby indicating that a small, but non-negligible portion of the men in the sample have more than two wives. Research by Reniers and Tfaily $(2008,2010)$ shows that HIV transmission risk is higher for women living in polygamous unions. This is not because the absolute number of partners is larger than in the case of serial monogamy (at least not over the entire lifespan), but because of the simultaneity of the concurrent relationships. In other words there exists a network effect, as an infected person cannot only infect his/her partner, but the entire network. This effect is particularly important as the HIV transmission risk is higher for recently infected individuals since an HIV positive person's viral load peaks in the first months after seroconversion. Therefore, adequate and effective protection strategies are particularly important for women living in polygamous relationships. ${ }^{8}$ The average age at current marriage is 20 years, with a minimum value of twelve. Officially, in Malawi 16-year-olds are allowed to marry with the consent of their parents. Unfortunately it is still observed that girls get married at an even earlier age, particularly in the North of the country where the girl's parents receive bridewealth which is then sometimes used to settle loans. ${ }^{9}$

\subsection{Household and Background Characteristics}

In addition to the empowerment variables just mentioned, a number of control variables are included in the analysis. After each interview, the interviewer had to comment on relative household wealth compared to the village average on a scale of one to five, where one indicates poorest and five richest. The variable relative wealth is used as a measure of household wealth in order to distinguish between the empowerment effect of personal income as discussed above and family wealth in general. ${ }^{10}$ Further, controls for family structure are added such as the number of living children and the number of marriages during a respondent's lifetime. In rural Malawi, wife inheritance is still a rather common phenomenon. In other words, it is widely accepted for a brother or another male relative of the deceased to marry the widow. The main intention of this institution is to ensure financial support for the widow as well as for her children. Partly, this can be understood in the larger context of "ties of dependence" in African social life, i.e. the occurence of patron-client ties together with the "moral obligation to support needy kin" (Swidler, 2007, p. 148). Needless to say, the social status of the widow will be lowered by the fact that she is financially dependent from her late husband's relatives. Even worse, if the deceased spouse was an AIDS victim, a larger number of previous marriages might be associated with both a lower social status as well as with an increased HIV risk. ${ }^{11}$

I also control for the number of people known to the respondent who have died from AIDS. This is meant to capture effects related to awaressness as well as fatalistic beliefs. Put differently, the more friends and relatives one has lost to AIDS, the more one might be inclined to view death from HIV as determined by fate (Kaler, 2003, p. 356). Lastly, controls for age and region of residence are included. On average, survey respondents are 36 years old and are more or less equally distributed across the three regions with $36 \%$ living in the Central region, $31 \%$ in the North, and $33 \%$ in the South. As mentioned above, the

\footnotetext{
${ }^{8}$ Reniers and Tfaily $(2008,2010)$ study the relationship between polygyny and HIV and identify a positive individuallevel correlation (i.e. women in polygamous unions are more likely to get infected with HIV), and a negative ecological correlation (i.e. in regions where polygyny is common, HIV prevalence tends to be lower).

${ }^{9}$ In 2009, the legal age of marriage has been subject of a rather heated public debate in Malawi, see also: http://www.ipsnews.net/2009/08/rights-sweet-16-marriages-cause-controversy-in-malawi/

${ }^{10}$ The link between wealth and HIV risk appears to be somewhat more fragile, though, as depending on the context and wealth measure that is used, previous studies find positive, negative, or even insignificant effects. See, for example, Opuni et al. (2011).

${ }^{11}$ Even though the variable number of marriages is linked to social status, it cannot be employed as a measure of empowerment since it does not allow us to distinguish between cases where a wife with several previous marriages was empowered and cases where she was not. Nevertheless, due to its linkages to HIV risk and social status, the number of previous marriages is an important control.
} 
three regions in themselves are rather homogenous with respect to ethnicity and religion. Using religion and ethnicity as controls does not add explanatory power to the regression as the estimated coefficients turn insignificant once that regional dummies are inluded. Therefore, the effects of ethnicity and religion on HIV prevention methods should sufficiently be captured by a regional dummy.

\section{HIV Prevention and Empowerment}

I create a panel data set based on the first five waves of the MDICP and use a linear probability model to estimate the effect of women's empowerment on the use and acceptance of HIV prevention methods.

$$
\begin{gathered}
y_{i t}=\mathbf{x}_{i t}^{\prime} \beta+\eta_{i}+\lambda_{t}+\varepsilon_{i t} \\
\text { for } t=1998,2001,2004,2006,2008
\end{gathered}
$$

Since the same individuals were interviewed repeatedly in the survey, individual-specific fixed effects can be used in order to take into account time-invariant unobserved heterogeneity. Further, time dummies are included in order to control for time trends in the data. Over the time period observed, several HIV prevention campaigns have been run in rural Malawi. One would therefore expect the level of knowledge and awareness with respect to HIV risk and prevention to be higher in 2008 than in 1998. In addition, while urban areas have witnessed a decline in HIV infection rates over the past decade, rural areas have seen an increase in HIV prevalence (UNAIDS, 2010, p. 18). Time dummies are meant to adequately capture this development. Since both dependent variables are Bernoulli variables, heteroskedasticity is present by construction and therefore heteroskedasticity-consistent standard errors shall be used (Angrist and Pischke, 2009, pp. 45-48; Arellano, 2003; Wooldridge, 2002, pp. 256-280). The following four specifications are estimated:

1. Linear probability model with random effects, i.e. $E\left(\eta_{i} \mid x_{i}\right)=E\left(\eta_{i}\right)=0$, without time dummies $\lambda_{t}$

2. Linear probability model with individual-specific fixed effects $\eta_{i}$, without time dummies $\lambda_{t}$

3. Linear probability model with time fixed effects $\lambda_{t}$, as well as random effects, i.e. $E\left(\eta_{i} \mid x_{i}\right)=0$

4. Linear probability model with two-way fixed effects (individual-specific FE $\eta_{i}$ and time FE $\lambda_{t}$ )

Throughout the analysis, random effects is used as a benchmark model. This is supported by the fact that for all specifications, the Breusch-Pagan Lagrange multiplier test strongly suggests the use of a random effects specification instead of pooled OLS. In other words, there are significant differences across units and using pooled OLS would not be appropriate (Breusch and Pagan, 1980). As abovementioned, I also estimate a fixed effects specification in order to account for unobserved heterogeneity. This is in line with the results from the Hausman (1978) test which suggests that fixed effects are preferable to random effects. Nevertheless, in the following the results from both the random as well as the fixed-effects specification are discussed as the central findings hold for both the fixed as well as the random effects specification.

It has to be noted that both the fixed as well as the random effects model assume that unobserved individual-specific heterogeneity (as expressed by the parameter $\eta_{i}$ ) is time-constant. In the present context, this implies that unobservable characteristics that influence both a woman's decision to use HIV prevention as well as her level of empowerment, are assumed to not change over time (Angrist and Pischke, 2009, pp. 243-247; Cameron and Trivedi, 2005, pp. 700-707). Put differently, I assume that a person who is careful and responsible (i.e. an attitude that is difficult to measure, but that potentially 
affects both one's protection decision as well as one's efforts at school or at work, and thereby the personal empowerment variables) will be this way throughout the entire period of study. Potential concerns with this assumption stem from the fact that HIV awareness campaigns could have an effect on attitudes, e.g. an individual might be even more careful after being informed about the threat of HIV. However, the potential for such an effect is insofar limited as I also include time dummies which are meant to pick up the impact of campaigns on prevention efforts. The assumption of time-constant individual-specific heterogeneity is also supported when comparing estimates of $\eta_{i}$ for different time periods: I re-estimate the model for the time period from 1998-2001 and 2004-2008, separately, and perform t-tests of differences in means between the estimated individual-specific effects. The null hypothesis of no significant differences cannot be rejected for any of the four specifications described above. It therefore appears reasonable to assume that individual-specific effects are time-constant. Detailed results can be found in the appendix in Table 16 and Table 17. In a nutshell, issues related to simultaneity are meant to be met by including both fixed effects as well time dummies. Reverse causality does not pose difficulties in this setting, either, as it is hard to imagine a situation whereby a woman would become more empowered because she has used adequate HIV prevention. Rather, we would expect that it is empowerment that makes her choose safe and effective HIV prevention methods.

The main drawback of the linear probability model is the potential occurence of out-of-sample predictions. On average, the fitted values from my analysis are very close to the actual ones, which can be seen as evidence in favor of the prediction quality of the model used. Nevertheless, out-of-sample predictions do occur, as it is rather common in linear probability models (for detailed results, see Table 14 and Table 15 in the appendix). However, since the aim of this paper is not to make predictions of the dependent variable, but rather to understand its determinants, the issue of out-of-sample predictions is not particularly relevant in this context. Nevertheless, I also consider non-linear estimation methods and the results do not change qualitatively. Coefficient estimates from random and conditional fixed effects logit with bootstrapped standard errors can be found in the robustness section in Chapter 5.2. The results from conditional fixed effects logit have to be interpreted very carefully, though, as there might be a bias due to the incidental parameter problem (Coupé, 2005; Greene, 2002; Lancaster, 2000). Provided that the inclusion of fixed effects is crucial to my analysis in order to account for unobserved heterogeneity in the data, I prefer to use a linear probability model. Furthermore, since the alternative would be to risk biased estimates (due to the incidental parameter problem) together with the rather arbitrary distribution assumptions involved with the use of non-linear models, out-of-sample predictions appear to be the lesser of two evils.

\subsection{Determinants of Spousal Communication}

Table 2 provides estimation results for the likelihood of HIV-related spousal communication. As explained in the theoretical considerations in Chapter 2, personal empowerment of women (resulting from e.g. education and own income) can be expected to promote HIV-related spousal communication, which might then lead to preventive measures. Educational attainment is associated with an increase in the probability that a woman talks with her spouse about the risk of HIV. This effect is statistically significant for the specification with random effects and time fixed effects. Since hardly any changes occur in the level of education over time, the effect turns insignificant once that individual-specific fixed effects are included. Not surprisingly, women who generate their own income are significantly more likely to discuss HIV-related issues with their husbands. The reference group in this case are women who did not have any personal income during the past year. Financial independence enables partners to meet at eye level. ${ }^{12}$

\footnotetext{
${ }^{12}$ On the effect of financial independence on female decision-making power within the household, see e.g. Ashraf et al. $(2010)$.
} 
Therefore, the less financially dependent a woman is from her spouse, the more comfortable she will probably feel to talk with him about adequate prevention methods. Further, it will also be easier for her to stand up against him if necessary and to e.g. confront him about a suspected infidelity. The effect of earnings is particularly important for medium-level incomes, and it is statistically significant for all four specifications employed. For women in the low-income group, I find a smaller, though still significant, effect. This suggests that their earnings might be far from sufficient in order to achieve financial independence. The estimated coefficient of the number of languages that a respondent knows is positive and significant for the first three specifications. As aforementioned, language skills can be expected to enlarge a woman's circle of social interaction, thereby contributing to empowerment as well.

Table 2 further displays the effects of interpersonal empowerment on HIV-related spousal communication. Awareness of exit options from marriage is proxied by variables measuring acceptable reasons for a woman to leave her husband. Women who consider violence and infidelity as appropriate reasons to leave, are significantly more likely to discuss HIV risk with their spouse. The same holds for those who would leave their spouse if he did not allow family planning. The number of co-wives is also associated with a higher likelihood of spousal communication, although this effect turns insignificant once that individualspecific and time fixed effects are being included. The older a woman was when she got married to her (current) husband, the less likely it is that she will have talked with him about the risk of HIV. This could reflect society's expectation for women to get married when they are still young. In other words, a woman who gets married at an older age might have a lower social status. She might also be older because she re-married after a divorce or got married following the tradition of wife inheritance. All of the aforementioned reasons will cause a woman who marries at an older age to have lower social status. If this translates into less empowerment in the context of her intimate relationship, it is understandable why it is less likely for her to advice her spouse about the risk of HIV.

With respect to background characteristics, relative wealth of a respondent's family is positively associated with spousal communication. However, this effect is only significant if time trends are included in the regression equation. The more children a woman has, the more likely it is that she talks with her spouse about HIV. This potentially reflects the perception of joint fates and care for the welfare of the children. Similar results have been found by Zulu and Chepngeno (2003) who find that women will often mention the risk of their children becoming orphans in HIV-related discussions with their spouse. The effect of the number of people known to the respondent who have died from AIDS is inconclusive as the sign of the estimated coefficients changes from positive to negative once that time trends are being controlled for. Potentially fatalistic beliefs are at work here: Overall, the more AIDS victim someone knows, the more worried about HIV that person will become, which could lead to an increase in prevention efforts. However, over the time of the study, AIDS prevalence has increased in rural Malawi. This could cause people to believe that getting infected with HIV is their fate rather than an event that can be prevented with adequate measures (Kaler, 2003, p. 356). As expected, age is significantly associated with an increase in the probability for spousal communication since the older someone is, the more time she has had to talk about HIV with her spouse. The estimated coefficient of age turns negative once time dummies are included as the time effect described above is then captured by the dummy.

I conduct a Wald test of joint significance of the coefficients which results in a Chi-square (20) statistic of 264.58. Therefore, the null that all coefficients are equal to zero can be rejected on all conventional significance levels. For the personal empowerment variables, the Wald test yields a Chi-square (5) test statistic of 75.41; for the interpersonal empowerment variables, the Chi-square (7) test statistic is 52.08 . Thus, for both dimensions of women's empowerment we can reject the null of joint insignificance on the $1 \%$ level. To sum it up it can be said that the empirical results provide convincing support for hypothesis H1, i.e. as women's bargaining power increases, so does the probability for HIV-related spousal communication. 
Table 2: Determinants of spousal communication about HIV

I estimate a linear probability model using panel data from 1998-2008. Robust standard errors are indicated in parentheses $\left(* * * \mathrm{p}<0.01,{ }^{* *} \mathrm{p}<0.05,{ }^{*} \mathrm{p}<0.1\right)$.

\begin{tabular}{|c|c|c|c|c|}
\hline spousal communication & (1) Random Effects & (2) Fixed Effects & (3) Time Dummy & (4) Two-Way FE \\
\hline \multicolumn{5}{|c|}{ Empowerment (personal) } \\
\hline \multirow[t]{2}{*}{ education } & $0.015^{* * *}$ & 0.001 & $0.006^{* *}$ & -0.003 \\
\hline & $(0.003)$ & $(0.009)$ & $(0.003)$ & $(0.009)$ \\
\hline \multirow[t]{2}{*}{ low earnings } & $0.046^{* *}$ & $0.041^{* *}$ & 0.004 & 0.022 \\
\hline & $(0.020)$ & $(0.021)$ & $(0.019)$ & $(0.021)$ \\
\hline \multirow[t]{2}{*}{ medium earnings } & $0.075^{* * *}$ & $0.050 * *$ & $0.031^{*}$ & $0.038^{*}$ \\
\hline & $(0.019)$ & $(0.020)$ & $(0.018)$ & $(0.020)$ \\
\hline \multirow[t]{2}{*}{ high earnings } & $0.064^{* * *}$ & $0.038^{*}$ & 0.028 & 0.029 \\
\hline & $(0.019)$ & $(0.021)$ & $(0.018)$ & $(0.020)$ \\
\hline \multirow[t]{2}{*}{ language } & $0.099^{* * *}$ & $0.065 * *$ & $0.050 * * *$ & 0.052 \\
\hline & $(0.020)$ & $(0.032)$ & $(0.019)$ & $(0.032)$ \\
\hline \multicolumn{5}{|c|}{ Empowerment (interpersonal) } \\
\hline \multirow[t]{2}{*}{ no financial support } & 0.009 & -0.001 & -0.004 & -0.003 \\
\hline & $(0.011)$ & $(0.012)$ & $(0.011)$ & $(0.012)$ \\
\hline \multirow[t]{2}{*}{ violence } & $0.025^{*}$ & 0.021 & $0.023^{*}$ & 0.021 \\
\hline & $(0.013)$ & $(0.013)$ & $(0.013)$ & $(0.013)$ \\
\hline \multirow[t]{2}{*}{ infidelity } & $0.048^{* * *}$ & $0.026^{*}$ & 0.020 & 0.018 \\
\hline & $(0.014)$ & $(0.015)$ & $(0.013)$ & $(0.015)$ \\
\hline \multirow[t]{2}{*}{ HIV infected } & 0.001 & 0.013 & 0.001 & 0.008 \\
\hline & $(0.012)$ & $(0.013)$ & $(0.012)$ & $(0.013)$ \\
\hline \multirow[t]{2}{*}{ no family planning } & $0.024^{* *}$ & $0.020^{*}$ & $0.020^{*}$ & 0.017 \\
\hline & $(0.011)$ & $(0.012)$ & $(0.011)$ & $(0.011)$ \\
\hline \multirow[t]{2}{*}{ number of wives } & $0.009^{*}$ & 0.007 & -0.009 & -0.009 \\
\hline & $(0.006)$ & $(0.007)$ & $(0.006)$ & $(0.007)$ \\
\hline \multirow[t]{2}{*}{ age at marriage } & $-0.008^{* * *}$ & -0.012 & $-0.005^{* *}$ & -0.012 \\
\hline & $(0.002)$ & $(0.009)$ & $(0.002)$ & $(0.009)$ \\
\hline \multicolumn{5}{|c|}{ Household and background characteristics } \\
\hline \multirow[t]{2}{*}{ relative wealth } & 0.010 & -0.000 & $0.011^{*}$ & 0.010 \\
\hline & $(0.007)$ & $(0.007)$ & $(0.007)$ & $(0.007)$ \\
\hline \multirow[t]{2}{*}{ children } & $0.019^{* * *}$ & 0.008 & $0.014^{* * *}$ & 0.010 \\
\hline & $(0.004)$ & $(0.008)$ & $(0.004)$ & $(0.008)$ \\
\hline \multirow[t]{2}{*}{ number of marriages } & 0.004 & 0.043 & -0.020 & 0.039 \\
\hline & $(0.017)$ & $(0.047)$ & $(0.017)$ & $(0.047)$ \\
\hline \multirow[t]{2}{*}{ AIDS victims } & $0.002^{* * *}$ & -0.001 & -0.001 & -0.002 \\
\hline & $(0.001)$ & $(0.001)$ & $(0.001)$ & $(0.001)$ \\
\hline \multirow[t]{2}{*}{ age } & $0.010^{* * *}$ & $0.019^{* *}$ & -0.006 & $-0.022^{* *}$ \\
\hline & $(0.004)$ & $(0.008)$ & $(0.004)$ & $(0.009)$ \\
\hline \multirow[t]{2}{*}{ age squared } & $-0.000 * *$ & 0.000 & 0.000 & $0.000^{*}$ \\
\hline & $(0.000)$ & $(0.000)$ & $(0.000)$ & $(0.000)$ \\
\hline Constant & $0.364^{* * *}$ & 0.057 & $1.044^{* * *}$ & $1.557^{* * *}$ \\
\hline & $(0.078)$ & $(0.198)$ & $(0.084)$ & $(0.237)$ \\
\hline region dummies & Yes & omitted & Yes & omitted \\
\hline time dummies & No & No & Yes & Yes \\
\hline Observations & 3,771 & 3,771 & 3,771 & 3,771 \\
\hline Number of respondents & 1,211 & 1,211 & 1,211 & 1,211 \\
\hline R2 Within & 0.129 & 0.177 & 0.195 & 0.200 \\
\hline R2 Between & 0.0579 & 0.00136 & 0.111 & 0.0402 \\
\hline R2 Overall & 0.0684 & 0.00191 & 0.143 & 0.0878 \\
\hline Breusch-Pagan (lm) & 176.4 & Breusch-Pagan (1 & value) & 0 \\
\hline Hausman-test (chi2) & 247.4 & Hausman-test (p- & alue) & 0 \\
\hline
\end{tabular}




\subsection{Determinants of Acceptance of Condom Use}

Table 3 shows estimates for the relationship between women's empowerment and acceptance of condom use. An important determinant of personal empowerment, education, is significantly associated with accepting condoms with one's spouse. As it is the case with spousal communication, the estimated coefficient of education turns insignificant once that fixed effects are included. Again, this is probably because the majority of the respondents are above school age and therefore education does not vary much over time. When it comes to earnings, a statistically significant effect on the acceptance of condom use can only be detected for women in the highest income group and the effect is not robust to changes in the specification. In other words, at lower levels, own income does not empower women sufficiently to demand condom use from their husband. It also has to be kept in mind that one could easily think of other factors rendering condom use in the context of marriage not to be the preferred option. As aforementioned, couples might decide not to use condoms for cultural reasons, or because they want to get pregnant, or simply because both partners got tested for the virus and are faithful to each other.

Acceptable reasons for a wife to leave her spouse can be seen as expressions of interpersonal empowerment. Women who consider lack of financial support to be an adequate reason for a separation are significantly more likely to be in favor of condom use with their spouse. As expected, women who would leave their husband if he had HIV or did not allow family planning methods, are also more inclined to accept the use of condoms. This effect is statistically significant and robust to all four specifications. This suggests that women who are aware of the danger of HIV and who know how to protect themselves will do so with their partner and will prefer to risk their relationship rather than to risk their life. The more co-wives a woman is living together with, the more open she is towards using condoms with her husband. In the case of concurrent partnerships, i.e. wives and co-wives living on the same compound, the threat of infection is probably much more real and direct, which will then lead to increased prevention efforts.

With respect to background characteristics, an increase in relative household wealth negatively affects the acceptance of condom use. Again, it can be argued that the more financial security a woman has to lose, the less she will be ready to risk it. Of course, it can be argued that risking one's life by not using precautions against a deadly disease is rather irrational, however this might reflect time inconsistencies in preference structures: in the long run, it would be rational and utility-maximizing to use HIV protection. However, in the short run, women - and especially those who are financially dependent on their spouse might be facing a trade-off between HIV risk and material security. Again, this notion of transactional sex has to be understood in the larger societal context of "ties of dependence" (Swidler, 2007, p. 148). The number of children does not have a significant effect on condom use within marriage. Potentially, this results from two opposing effects outweighing each other: On the one hand, the more children a couple has, the larger is the incentive to protect them from becoming orphans and to use adequate HIV protection. On the other hand, couples who use condoms for birth spacing will also have a smaller number of children. Since these two effects work in opposite directions, this might serve as an explanation for the insignificance of the estimated coefficient on the number of children. The acceptance of condom use is positively associated with the number of times that a woman has been married. This might reflect the influence of widows of AIDS victims among remarrying women. In other words, widows will be painfully aware of the risks associated with HIV and unprotected sex. Alternatively, women who remarry might have divorced from their previous partner because he did not accept HIV prevention measures or because she perceived him as an HIV infection risk (Reniers, 2008). Again, this effect is not robust to specifications including fixed effects. Age is significantly associated with an increase in acceptance of condom use. This reflects a time effect because the longer someone lives, the higher the likelihood of him ever using (and accepting) condoms. However, if time dummies are included the estimated coefficient turns negative. Again, this is probably because the time dummy captures the time effect just mentioned. 
The Wald test of joint significance of the coefficients results in a Chi-square (20) statistic of 166.57. Therefore, the null that all coefficients are equal to zero can be rejected on the $1 \%$ significance level. For the personal empowerment variables, the Wald test yields a Chi-square (5) test statistic of 11.68 which corresponds to a p-value of $3.94 \%$. For the interpersonal empowerment variables, the Chi-square (7) test statistic is 44.01. Thus, for the interpersonal dimension of women's empowerment we can again reject the null of joint insignificance on all conventional significance levels. In a nutshell, the empirical results provide strong support for hypothesis H2, i.e. an increase in women's empowerment promotes the acceptance of condom use within marriage. 
Table 3: Determinants of acceptance of condom use with spouse

I estimate a linear probability model using panel data from 1998-2008. Robust standard errors are indicated in parentheses $\left(* * * \mathrm{p}<0.01,{ }^{*} * \mathrm{p}<0.05,{ }^{*} \mathrm{p}<0.1\right)$.

\begin{tabular}{|c|c|c|c|c|}
\hline condom use $\mathrm{w}$ spouse & (1) Random Effects & (2) Fixed Effects & (3) Time Dummy & (4) Two-Way \\
\hline \multicolumn{5}{|c|}{ Empowerment (personal) } \\
\hline \multirow[t]{2}{*}{ education } & $0.009^{* * *}$ & 0.000 & 0.005 & -0.000 \\
\hline & $(0.003)$ & $(0.014)$ & $(0.003)$ & $(0.014)$ \\
\hline \multirow[t]{2}{*}{ low earnings } & 0.029 & -0.008 & -0.006 & -0.007 \\
\hline & $(0.025)$ & $(0.031)$ & $(0.025)$ & $(0.031)$ \\
\hline \multirow[t]{2}{*}{ medium earnings } & 0.031 & -0.013 & -0.005 & -0.012 \\
\hline & $(0.025)$ & $(0.031)$ & $(0.025)$ & $(0.031)$ \\
\hline \multirow[t]{2}{*}{ high earnings } & $0.044^{*}$ & 0.004 & 0.015 & 0.005 \\
\hline & $(0.025)$ & $(0.031)$ & $(0.025)$ & $(0.031)$ \\
\hline \multirow[t]{2}{*}{ language } & 0.010 & -0.022 & -0.016 & -0.028 \\
\hline & $(0.020)$ & $(0.041)$ & $(0.020)$ & $(0.041)$ \\
\hline \multicolumn{5}{|c|}{ Empowerment (interpersonal) } \\
\hline \multirow[t]{2}{*}{ no financial support } & $0.036^{* *}$ & 0.009 & $0.029^{*}$ & 0.008 \\
\hline & $(0.018)$ & $(0.022)$ & $(0.018)$ & $(0.022)$ \\
\hline \multirow[t]{2}{*}{ violence } & 0.013 & -0.006 & 0.012 & -0.001 \\
\hline & $(0.019)$ & $(0.023)$ & $(0.018)$ & $(0.023)$ \\
\hline \multirow[t]{2}{*}{ infidelity } & -0.006 & -0.002 & -0.031 & -0.003 \\
\hline & $(0.019)$ & $(0.023)$ & $(0.019)$ & $(0.023)$ \\
\hline \multirow[t]{2}{*}{ HIV infected } & $0.038^{* *}$ & $0.049^{* *}$ & $0.035^{*}$ & $0.041^{*}$ \\
\hline & $(0.019)$ & $(0.023)$ & $(0.019)$ & $(0.024)$ \\
\hline \multirow[t]{2}{*}{ no family planning } & $0.064^{* * *}$ & $0.059^{* * *}$ & $0.060^{* * *}$ & $0.057^{* *}$ \\
\hline & $(0.019)$ & $(0.022)$ & $(0.019)$ & $(0.022)$ \\
\hline \multirow[t]{2}{*}{ number of wives } & $0.038^{* * *}$ & 0.023 & $0.032 * * *$ & 0.020 \\
\hline & $(0.011)$ & $(0.015)$ & $(0.011)$ & $(0.016)$ \\
\hline \multirow[t]{2}{*}{ age at marriage } & -0.003 & 0.001 & -0.002 & 0.001 \\
\hline & $(0.002)$ & $(0.007)$ & $(0.002)$ & $(0.007)$ \\
\hline \multicolumn{5}{|c|}{ Household and background characteristics } \\
\hline \multirow[t]{2}{*}{ relative wealth } & -0.013 & $-0.025^{* *}$ & -0.015 & -0.020 \\
\hline & $(0.010)$ & $(0.012)$ & $(0.010)$ & $(0.013)$ \\
\hline \multirow[t]{2}{*}{ children } & 0.003 & -0.007 & 0.001 & -0.006 \\
\hline & $(0.005)$ & $(0.012)$ & $(0.005)$ & $(0.012)$ \\
\hline \multirow[t]{2}{*}{ number of marriages } & $0.030^{*}$ & -0.049 & 0.009 & -0.035 \\
\hline & $(0.017)$ & $(0.061)$ & $(0.017)$ & $(0.062)$ \\
\hline \multirow[t]{2}{*}{ AIDS victims } & $0.002^{* *}$ & 0.000 & -0.000 & 0.000 \\
\hline & $(0.001)$ & $(0.002)$ & $(0.001)$ & $(0.002)$ \\
\hline \multirow[t]{2}{*}{ age } & 0.001 & $0.040^{* * *}$ & $-0.007^{*}$ & $0.053^{* * *}$ \\
\hline & $(0.004)$ & $(0.011)$ & $(0.004)$ & $(0.017)$ \\
\hline \multirow[t]{2}{*}{ age squared } & -0.000 & -0.000 & 0.000 & -0.000 \\
\hline & $(0.000)$ & $(0.000)$ & $(0.000)$ & $(0.000)$ \\
\hline Constant & 0.110 & $-0.685^{* * *}$ & $0.524^{* * *}$ & $-1.299^{* *}$ \\
\hline & $(0.081)$ & $(0.219)$ & $(0.088)$ & $(0.538)$ \\
\hline region dummies & Yes & omitted & Yes & omitted \\
\hline time dummies & No & No & Yes & Yes \\
\hline Observations & 3,815 & 3,815 & 3,815 & 3,815 \\
\hline Number of respondents & 1,251 & 1,251 & 1,251 & 1,251 \\
\hline R2 Within & 0.0213 & 0.0476 & 0.0436 & 0.0509 \\
\hline R2 Between & 0.0787 & $2.58 \mathrm{e}-06$ & 0.112 & 0.000345 \\
\hline R2 Overall & 0.0487 & 0.00203 & 0.0745 & 0.000356 \\
\hline Breusch-Pagan (lm) & 27.45 & Breusch-Pagan ( $\mathrm{p}$ & value) & $8.04 \mathrm{e}-08$ \\
\hline Hausman-test (chi2) & 97.91 & Hausman-test ( $\mathrm{p}^{-}$ & alue) & 0 \\
\hline
\end{tabular}




\section{$5 \quad$ Validation and Robustness Testing}

\subsection{Regional Differences}

As already discussed in the data part, there are notable differences between the three regions included in the MDICP. Probably the most important difference can be found with respect to HIV prevalence, which is $9.6 \%$ in the South, but only $4.8 \%$ in the Central region and $4.4 \%$ in the North. Also the preferred methods of HIV prevention vary across regions: Condom use is most accepted in the South (40.8\%), whereas in the other two regions only about $25 \%$ of the respondents are in favor of using condoms with their spouse. Spousal communication about HIV risk, though, is more prevalent in the Central and Northern region. However, with less than 10 percentage points the difference between regions is not as large as with respect to condom use. In order to accomodate for these regional differences, the equations are re-estimated for each region separately. Table 4 shows the results of the linear probability model with time fixed effects and two-way fixed effects for spousal communication. Table 5 provides results for the same two specifications with acceptance of condom use as the dependent variable. Detailed results for specification 1 - 4 in each of the three regions are provided in the appendix.

Spousal communication is positively affected by education, but this effect is only significant in the Central region. It has to be borne in mind, though, that average education levels are significantly higher in the North and in the Central region than in the South (6.08 and 3.23 years, compared to 1.69 years). With average educational attainment being so low in the South, it would be very surprising to find any effect of it on HIV prevention. Similarly, a positive and statistically significant effect of earnings can only be detected in the Central region which is most likely due to the fact that average earnings in the Central region are more than twice as high as in the South. It remains unclear, though, why the effect is insignificant in the North, where average earnings are even higher. Language knowledge, on the other hand, only has a statistically significant effect on spousal communication in the Southern region. As aforementioned, proficiency in another language is expected to expand possibilities for social interaction and therefore information and awareness about HIV protection. This effect might be particularly important in the South because it is somewhat more diverse than the other regions: The South is populated by two main ethnic groups, the Lomwe and the Yao, whereas the Central and the Northern regions are each dominated by one ethnical group, the Chewa and the Tumbuka, respectively.

In the South, women are more likely to advice their spouse about the risk of HIV if they consider it as acceptable to leave their spouse if he does not allow family planning. In the Central region, the older a woman is at marriage, the less likely it is for her to discuss HIV risk with her husband. Again, this can be explained with the social status effect of widowed and divorced women. When it comes to background characteristics, in all three regions a larger number of children is associated with a higher probability for spousal communication. Again, this is most likely linked to the fact that parents want to avoid that their children become orphans. The number of previous marriages has a positive effect on spousal communication in the Central region, but a negative effect in the Southern region. For the North, the effect is not statistically significant. Age has a negative effect on spousal communication in the South. As before, the negative sign can probably be explained with the inclusion of time dummies that pick up the time trend in the data.

The acceptance of condom use is positively affected by education, however this effect is only significant in the Southern region. The estimated coefficient of own earnings is negative and statistically significant in the North, where the (absolute) effect is largest for low incomes. As before, the reference group are women without own income. In the South, the effect of earnings is positive and statistically significant, but only for the highest income group. This suggests that there might be important threshold effects: in other words, in the Northern region women's incomes might need to rise beyond a certain level in 
order to surpass an amount where financial independence is no longer traded against material security provided by the husband. One also has to take into account that the North of Malawi is less poor than the South: People in the North do not only enjoy higher educational attainment on average, but also tend to rely less on subsistence farming due to the availability of salaried jobs in the tobacco production. Even though in absolute terms, all participants in the MDICP can be considered as poor, there are still important relative differences. In other words, for families in the North, the husband's income might be sufficient to cater for the family, whereas in the South, women might be forced to contribute to the family income for economic reasons. However, once that the wive's contribution to the family income in the South exceeds a certain threshold, her bargaining power will also increase.

In the Central and Southern Region, leaving one's husband for infidelity is associated with a lower probability of accepting condoms, whereas in the North the estimated coefficient is positive. One could argue that women in the North, where polygamy is more prevalent than in the other regions, will be more likely to accept condoms in the first place because they are aware of their increased risk due to the presence of concurrent partnerships. A potential explanation for the negative sign in the Central and Southern districts might be that women will trust their spouses until they give them reason not to, rather than using condoms just in case. However, if they detect an infidelity, women in the Central and Southern region are more likely to leave their spouse. Confirming what we have seen before, women who find it acceptable to leave a partner who is infected with HIV or who does not allow family planning are also more inclined to use condoms with their spouse. The estimated coefficient is positive and statistically significant in the North as well as in the South. In the Central region, the number of co-wives will significantly increase the acceptance of condom use in marriage. The effect of age at marriage is negative and only statistically significant in the South. The same holds for relative household wealth. A positive effect of the number of children on condom use among married couples can only be found in the Central region. In the North, the number of previous marriages will decrease the likelihood of accepting condoms.

To sum it up it can be said that the effect of women's bargaining power on HIV protection differs among regions and that policy programs should take regional differences into account when designing empowerment programs aimed at influencing HIV prevention. 
Table 4: Determinants of spousal communication about HIV (by region)

I estimate a linear probability model using panel data from 1998-2008. Robust standard errors are indicated in parentheses $\left(* * * \mathrm{p}<0.01,{ }^{* *} \mathrm{p}<0.05,{ }^{*} \mathrm{p}<0.1\right)$.

\begin{tabular}{|c|c|c|c|c|c|c|}
\hline \multirow{2}{*}{ spousal communication } & \multicolumn{2}{|c|}{ Central } & \multicolumn{2}{|c|}{ North } & \multicolumn{2}{|c|}{ South } \\
\hline & TD & TW FE & TD & TW FE & TD & TW FE \\
\hline \multicolumn{7}{|l|}{ Empowerment (personal) } \\
\hline \multirow[t]{2}{*}{ education } & 0.006 & -0.003 & 0.007 & 0.004 & 0.006 & -0.009 \\
\hline & $(0.004)$ & $(0.012)$ & $(0.005)$ & $(0.019)$ & $(0.006)$ & $(0.023)$ \\
\hline \multirow[t]{2}{*}{ low earnings } & 0.016 & 0.034 & -0.034 & -0.009 & 0.015 & 0.031 \\
\hline & $(0.032)$ & $(0.036)$ & $(0.029)$ & $(0.032)$ & $(0.036)$ & $(0.040)$ \\
\hline \multirow[t]{2}{*}{ medium earnings } & $0.050^{*}$ & $0.058^{*}$ & -0.008 & 0.016 & 0.024 & 0.018 \\
\hline & $(0.029)$ & $(0.034)$ & $(0.029)$ & $(0.032)$ & $(0.036)$ & $(0.040)$ \\
\hline \multirow[t]{2}{*}{ high earnings } & $0.063^{* *}$ & $0.067^{* *}$ & -0.022 & -0.018 & 0.007 & -0.005 \\
\hline & $(0.028)$ & $(0.032)$ & $(0.029)$ & $(0.032)$ & $(0.040)$ & $(0.045)$ \\
\hline \multirow[t]{2}{*}{ language } & 0.017 & 0.042 & 0.045 & -0.000 & $0.109^{* *}$ & 0.083 \\
\hline & $(0.023)$ & $(0.056)$ & $(0.037)$ & $(0.045)$ & $(0.052)$ & $(0.063)$ \\
\hline \multicolumn{7}{|c|}{ Empowerment (interpersonal) } \\
\hline \multirow[t]{2}{*}{ no financial support } & 0.003 & -0.008 & -0.019 & -0.007 & -0.014 & -0.015 \\
\hline & $(0.018)$ & $(0.020)$ & $(0.017)$ & $(0.017)$ & $(0.022)$ & $(0.025)$ \\
\hline \multirow[t]{2}{*}{ violence } & 0.028 & 0.030 & 0.025 & 0.020 & 0.011 & 0.010 \\
\hline & $(0.020)$ & $(0.021)$ & $(0.019)$ & $(0.019)$ & $(0.030)$ & $(0.033)$ \\
\hline \multirow[t]{2}{*}{ infidelity } & 0.015 & 0.005 & 0.014 & 0.016 & 0.034 & 0.037 \\
\hline & $(0.022)$ & $(0.024)$ & $(0.019)$ & $(0.021)$ & $(0.034)$ & $(0.037)$ \\
\hline \multirow[t]{2}{*}{ HIV infected } & 0.009 & 0.017 & 0.008 & 0.028 & -0.006 & -0.003 \\
\hline & $(0.019)$ & $(0.021)$ & $(0.020)$ & $(0.023)$ & $(0.021)$ & $(0.023)$ \\
\hline \multirow[t]{2}{*}{ no family planning } & 0.010 & 0.011 & -0.008 & -0.015 & $0.053^{* * *}$ & $0.044^{* *}$ \\
\hline & $(0.018)$ & $(0.019)$ & $(0.018)$ & $(0.019)$ & $(0.019)$ & $(0.020)$ \\
\hline \multirow[t]{2}{*}{ number of wives } & -0.002 & 0.002 & -0.008 & -0.009 & -0.024 & -0.032 \\
\hline & $(0.007)$ & $(0.010)$ & $(0.008)$ & $(0.011)$ & $(0.017)$ & $(0.021)$ \\
\hline \multirow[t]{2}{*}{ age at marriage } & $-0.010^{* *}$ & $-0.030^{* * *}$ & -0.006 & 0.002 & 0.000 & -0.001 \\
\hline & $(0.004)$ & $(0.011)$ & $(0.004)$ & $(0.037)$ & $(0.003)$ & $(0.012)$ \\
\hline \multicolumn{7}{|c|}{ Household and background characteristics } \\
\hline relative wealth & 0.003 & -0.000 & 0.014 & 0.008 & 0.006 & 0.007 \\
\hline & $(0.009)$ & $(0.011)$ & $(0.011)$ & $(0.013)$ & $(0.013)$ & $(0.014)$ \\
\hline children & $0.012^{* *}$ & 0.007 & $0.014^{*}$ & -0.009 & $0.015^{* *}$ & 0.020 \\
\hline & $(0.006)$ & $(0.011)$ & $(0.008)$ & $(0.017)$ & $(0.007)$ & $(0.015)$ \\
\hline number of marriages & 0.024 & $0.231^{* *}$ & -0.014 & 0.041 & $-0.064^{* *}$ & -0.068 \\
\hline & $(0.028)$ & $(0.090)$ & $(0.037)$ & $(0.134)$ & $(0.025)$ & $(0.060)$ \\
\hline AIDS victims & -0.000 & -0.001 & -0.001 & -0.000 & -0.001 & -0.004 \\
\hline & $(0.001)$ & $(0.002)$ & $(0.001)$ & $(0.002)$ & $(0.002)$ & $(0.003)$ \\
\hline age & -0.002 & -0.022 & -0.009 & 0.010 & -0.006 & $-0.039 * *$ \\
\hline & $(0.005)$ & $(0.014)$ & $(0.008)$ & $(0.017)$ & $(0.007)$ & $(0.018)$ \\
\hline age squared & 0.000 & 0.000 & 0.000 & -0.000 & 0.000 & 0.000 \\
\hline & $(0.000)$ & $(0.000)$ & $(0.000)$ & $(0.000)$ & $(0.000)$ & $(0.000)$ \\
\hline Constant & $1.013^{* * *}$ & $1.654^{* * *}$ & $1.137^{* * *}$ & 0.624 & $0.962 * * *$ & $1.861^{* * *}$ \\
\hline & $(0.120)$ & $(0.322)$ & $(0.161)$ & $(0.770)$ & $(0.168)$ & $(0.442)$ \\
\hline time dummies & Yes & Yes & Yes & Yes & Yes & Yes \\
\hline Observations & 1,398 & 1,398 & 1,314 & 1,314 & 1,059 & 1,059 \\
\hline Number of respondents & 459 & 459 & 385 & 385 & 367 & 367 \\
\hline R2 Within & 0.185 & 0.204 & 0.178 & 0.185 & 0.268 & 0.278 \\
\hline R2 Between & 0.0892 & 0.0244 & 0.126 & 0.00131 & 0.129 & 0.0667 \\
\hline R2 Overall & 0.126 & 0.0543 & 0.143 & 0.0600 & 0.174 & 0.118 \\
\hline Breusch-Pagan (lm) & & .03 & 39 & & & \\
\hline Breusch-Pagan (p-value) & & 0 & 1.30 & -10 & & \\
\hline Hausman-test (chi2) & & .36 & 95 & & & \\
\hline Hausman-test ( $\mathrm{p}$-value) & & 0 & ( & & & \\
\hline
\end{tabular}


Table 5: Determinants of acceptance of condom use with spouse (by region)

I estimate a linear probability model using panel data from 1998-2008. Robust standard errors are indicated in parentheses $\left(* * * \mathrm{p}<0.01,{ }^{* *} \mathrm{p}<0.05,{ }^{*} \mathrm{p}<0.1\right)$.

\begin{tabular}{|c|c|c|c|c|c|c|}
\hline \multirow{2}{*}{ condom use w spouse } & \multicolumn{2}{|c|}{ Central } & \multicolumn{2}{|c|}{ North } & \multicolumn{2}{|c|}{ South } \\
\hline & TD & TW FE & TD & TW FE & TD & TW FE \\
\hline \multicolumn{7}{|l|}{ Empowerment (personal) } \\
\hline \multirow[t]{2}{*}{ education } & 0.002 & -0.009 & -0.001 & -0.009 & $0.014^{*}$ & 0.027 \\
\hline & $(0.005)$ & $(0.017)$ & $(0.006)$ & $(0.026)$ & $(0.007)$ & $(0.037)$ \\
\hline \multirow[t]{2}{*}{ low earnings } & 0.032 & 0.039 & $-0.117^{* * *}$ & $-0.100^{*}$ & 0.049 & 0.063 \\
\hline & $(0.036)$ & $(0.044)$ & $(0.045)$ & $(0.055)$ & $(0.049)$ & $(0.068)$ \\
\hline \multirow[t]{2}{*}{ medium earnings } & 0.028 & 0.027 & $-0.082^{*}$ & -0.046 & 0.023 & 0.007 \\
\hline & $(0.035)$ & $(0.043)$ & $(0.047)$ & $(0.054)$ & $(0.051)$ & $(0.070)$ \\
\hline \multirow[t]{2}{*}{ high earnings } & 0.032 & 0.026 & $-0.090^{* *}$ & -0.058 & $0.115^{* *}$ & 0.071 \\
\hline & $(0.034)$ & $(0.043)$ & $(0.044)$ & $(0.053)$ & $(0.058)$ & $(0.076)$ \\
\hline \multirow[t]{2}{*}{ language } & -0.009 & 0.009 & -0.053 & -0.052 & -0.012 & -0.064 \\
\hline & $(0.026)$ & $(0.055)$ & $(0.042)$ & $(0.072)$ & $(0.049)$ & $(0.089)$ \\
\hline \multicolumn{7}{|c|}{ Empowerment (interpersonal) } \\
\hline \multirow[t]{2}{*}{ no financial support } & 0.036 & 0.011 & 0.030 & 0.005 & 0.022 & -0.020 \\
\hline & $(0.027)$ & $(0.033)$ & $(0.031)$ & $(0.036)$ & $(0.035)$ & $(0.045)$ \\
\hline \multirow[t]{2}{*}{ violence } & 0.016 & 0.022 & 0.013 & -0.004 & 0.024 & -0.030 \\
\hline & $(0.029)$ & $(0.035)$ & $(0.029)$ & $(0.035)$ & $(0.042)$ & $(0.056)$ \\
\hline \multirow[t]{2}{*}{ infidelity } & $-0.056^{*}$ & $-0.084^{* *}$ & 0.013 & 0.055 & $-0.087^{*}$ & 0.022 \\
\hline & $(0.030)$ & $(0.037)$ & $(0.029)$ & $(0.034)$ & $(0.046)$ & $(0.059)$ \\
\hline \multirow[t]{2}{*}{ HIV infected } & 0.001 & -0.016 & 0.047 & -0.000 & 0.046 & $0.096^{* *}$ \\
\hline & $(0.032)$ & $(0.039)$ & $(0.035)$ & $(0.044)$ & $(0.032)$ & $(0.039)$ \\
\hline \multirow[t]{2}{*}{ no family planning } & $0.078^{* * *}$ & 0.051 & 0.009 & 0.024 & $0.072^{* *}$ & $0.086^{* *}$ \\
\hline & $(0.029)$ & $(0.033)$ & $(0.037)$ & $(0.044)$ & $(0.033)$ & $(0.039)$ \\
\hline \multirow[t]{2}{*}{ number of wives } & 0.017 & 0.002 & $0.068^{* * *}$ & $0.063^{* * *}$ & -0.009 & -0.018 \\
\hline & $(0.019)$ & $(0.023)$ & $(0.015)$ & $(0.024)$ & $(0.027)$ & $(0.037)$ \\
\hline \multirow[t]{2}{*}{ age at marriage } & 0.001 & 0.017 & 0.004 & 0.008 & $-0.006^{* *}$ & -0.012 \\
\hline & $(0.003)$ & $(0.012)$ & $(0.003)$ & $(0.012)$ & $(0.003)$ & $(0.013)$ \\
\hline \multicolumn{7}{|c|}{ Household and background characteristics } \\
\hline relative wealth & -0.009 & -0.004 & -0.000 & -0.006 & $-0.039 * *$ & $-0.067 * * *$ \\
\hline & $(0.014)$ & $(0.019)$ & $(0.019)$ & $(0.024)$ & $(0.017)$ & $(0.024)$ \\
\hline children & -0.009 & $-0.027^{*}$ & $0.020^{* *}$ & 0.019 & 0.000 & 0.002 \\
\hline & $(0.007)$ & $(0.016)$ & $(0.009)$ & $(0.022)$ & $(0.008)$ & $(0.023)$ \\
\hline number of marriages & -0.003 & $-0.223^{*}$ & -0.027 & -0.014 & 0.026 & 0.025 \\
\hline & $(0.030)$ & $(0.126)$ & $(0.035)$ & $(0.085)$ & $(0.024)$ & $(0.079)$ \\
\hline AIDS victims & 0.000 & 0.002 & 0.001 & 0.002 & -0.002 & -0.005 \\
\hline & $(0.002)$ & $(0.003)$ & $(0.001)$ & $(0.002)$ & $(0.002)$ & $(0.004)$ \\
\hline age & -0.006 & 0.039 & -0.012 & $0.094^{* * *}$ & 0.001 & 0.008 \\
\hline & $(0.005)$ & $(0.026)$ & $(0.008)$ & $(0.029)$ & $(0.008)$ & $(0.036)$ \\
\hline age squared & 0.000 & -0.000 & 0.000 & -0.000 & -0.000 & -0.000 \\
\hline & $(0.000)$ & $(0.000)$ & $(0.000)$ & $(0.000)$ & $(0.000)$ & $(0.000)$ \\
\hline Constant & $0.452^{* * *}$ & -0.890 & $0.626^{* * *}$ & $-3.415^{* * *}$ & $0.624^{* * *}$ & 0.908 \\
\hline & $(0.112)$ & $(0.835)$ & $(0.181)$ & $(0.952)$ & $(0.171)$ & $(1.092)$ \\
\hline time dummies & Yes & Yes & Yes & Yes & Yes & Yes \\
\hline Observations & 1,407 & 1,407 & 1,319 & 1,319 & 1,089 & 1,089 \\
\hline Number of respondents & 467 & 467 & 393 & 393 & 391 & 391 \\
\hline R2 Within & 0.0632 & 0.0776 & 0.0432 & 0.0722 & 0.0582 & 0.0745 \\
\hline R2 Between & 0.0815 & 0.000167 & 0.130 & 0.00873 & 0.0475 & 0.0188 \\
\hline R2 Overall & 0.0649 & 0.00270 & 0.0640 & 0.00157 & 0.0527 & 0.0269 \\
\hline Breusch-Pagan (lm) & & & & & & 80 \\
\hline Breusch-Pagan ( $\mathrm{p}$-value) & 1.56 & -06 & 0.0 & 383 & & 852 \\
\hline Hausman-test (chi2) & & & & & & 58 \\
\hline Hausman-test (p-value) & 4.98 & -07 & 0.0 & 752 & 0.00 & 0342 \\
\hline
\end{tabular}




\subsection{Non-linear Estimation Methods}

As a robustness check, I re-estimate the previous specification using a non-linear estimation method, namely a logit model. Standard errors are computed by performing 250 bootstrap replications. Compared to the coefficient estimates from the linear probability model, the results do not change qualitatively.

Logit estimates for the determinants of spousal communication are given in Table 6. In specification 1 (random effects), the estimated coefficients from the logit model are highly comparable to those from the linear probability model, both in terms of sign and significance. The only difference between the two models can be found with respect to the effect that the respondent's family's wealth has on spousal communication. The coefficient is positive in both models, but only statistically significant in the logit estimation. In specification 2 and 4 (conditional fixed effects and two-way fixed effects) none of the estimated coefficients in the logit model turn out to be significant. As mentioned in the methodological considerations in Chapter 4, the results from conditional fixed effects logit have to be interpreted with caution as there might be a bias resulting from the incidental parameter problem (Coupé, 2005; Greene, 2002; Lancaster, 2000). The logit results from specification 3 (time dummies) are again similar to the results from the linear probability model, except that I do not find a significant effect for medium-level earnings in the logit model. Further, the estimated coefficients on no family planning and relative wealth are not statistically significant in the non-linear model. The number of previous marriages, however, has a negative and statistically significant impact on spousal communication in the logit estimation - as opposed to the linear estimation, where the effect was not significant.

The results for the acceptance of condom use can be found in Table 7 . The estimated coefficients from specification 1 and 4 (random and two-way fixed effects) are qualitatively very similar in the non-linear and linear estimation. More precisely, no differences can be found between the two models in terms of sign and statistical significance of the coefficients. In specification 2 (conditional fixed effects) the results only differ with respect to the coefficient on the square of age, which is significant in the logit estimation but not in the linear probabilty model. Lastly, in specification 3 (time dummies), using a non-linear estimation method results in more significant coefficients. Namely, in the logit results the estimated coefficients on education, infidelity, and relative wealth are statistically significant, whereas they are not in the linear model. At the same time, though, the coefficient on no financial support, which is significant in the linear probability model, loses its statistical significance in the logit estimation.

Summing up it can be said that the results do not change qualitatively when employing a non-linear instead of a linear estimation method, thereby providing support for the main hypothesis of this paper that women's empowerment promotes the use of adequate HIV prevention methods. 
Table 6: Logit estimates of determinants of spousal communication about HIV

I estimate a logit model using panel data from 1998-2008. Standard errors are computed by performing 250 bootstrap replications and are indicated in parentheses $\left(* * * \mathrm{p}<0.01,{ }^{* *} \mathrm{p}<0.05,{ }^{*} \mathrm{p}<0.1\right.$ ).

\begin{tabular}{|c|c|c|c|c|}
\hline spousal communication & (1) Random Effects & (2) Fixed Effects & (3) Time Dummy & (4) Two-Way FE \\
\hline \multicolumn{5}{|c|}{ Empowerment (personal) } \\
\hline \multirow[t]{2}{*}{ education } & $0.251^{* * *}$ & -0.326 & $0.190^{* *}$ & -0.353 \\
\hline & $(0.051)$ & $(6.111)$ & $(0.078)$ & $(7.392)$ \\
\hline \multirow[t]{2}{*}{ low earnings } & $0.544^{* *}$ & -0.266 & -0.219 & -0.460 \\
\hline & $(0.275)$ & $(5.337)$ & $(0.426)$ & $(10.426)$ \\
\hline \multirow[t]{2}{*}{ medium earnings } & $1.073^{* * *}$ & 0.094 & 0.447 & 0.033 \\
\hline & $(0.278)$ & $(5.090)$ & $(0.460)$ & $(13.027)$ \\
\hline \multirow[t]{2}{*}{ high earnings } & $0.907^{* * *}$ & -0.133 & 0.451 & -0.009 \\
\hline & $(0.266)$ & $(3.121)$ & $(0.411)$ & $(15.388)$ \\
\hline \multirow[t]{2}{*}{ language } & $1.367^{* * *}$ & -0.187 & $0.800^{*}$ & -0.411 \\
\hline & $(0.300)$ & $(8.647)$ & $(0.461)$ & $(43.341)$ \\
\hline \multicolumn{5}{|c|}{ Empowerment (interpersonal) } \\
\hline \multirow[t]{2}{*}{ no financial support } & 0.106 & -0.057 & -0.252 & -0.117 \\
\hline & $(0.189)$ & $(2.620)$ & $(0.309)$ & $(6.081)$ \\
\hline \multirow[t]{2}{*}{ violence } & $0.384^{*}$ & 0.524 & $0.691^{* *}$ & 0.686 \\
\hline & $(0.204)$ & $(3.515)$ & $(0.345)$ & $(9.343)$ \\
\hline \multirow[t]{2}{*}{ infidelity } & $0.736^{* * *}$ & -0.135 & 0.209 & -0.514 \\
\hline & $(0.213)$ & $(8.434)$ & $(0.348)$ & $(7.897)$ \\
\hline \multirow[t]{2}{*}{ HIV infected } & -0.001 & 0.545 & 0.074 & 0.567 \\
\hline & $(0.186)$ & $(3.832)$ & $(0.305)$ & $(5.864)$ \\
\hline \multirow[t]{2}{*}{ no family planning } & $0.413^{* *}$ & 0.097 & 0.416 & 0.346 \\
\hline & $(0.199)$ & $(4.296)$ & $(0.300)$ & $(6.345)$ \\
\hline \multirow[t]{2}{*}{ number of wives } & $0.245^{*}$ & -0.010 & -0.301 & -0.073 \\
\hline & $(0.132)$ & $(2.744)$ & $(0.216)$ & $(6.443)$ \\
\hline \multirow[t]{2}{*}{ age at marriage } & $-0.113^{* * *}$ & -0.216 & $-0.122^{* *}$ & -0.203 \\
\hline & $(0.032)$ & $(2.336)$ & $(0.057)$ & $(2.720)$ \\
\hline \multicolumn{5}{|c|}{ Household and background characteristics } \\
\hline \multirow[t]{2}{*}{ relative wealth } & $0.186^{*}$ & -0.157 & 0.205 & -0.132 \\
\hline & $(0.105)$ & $(2.826)$ & $(0.183)$ & $(3.567)$ \\
\hline \multirow[t]{2}{*}{ children } & $0.313^{* * *}$ & 0.003 & $0.325^{* * *}$ & -0.031 \\
\hline & $(0.066)$ & $(1.377)$ & $(0.101)$ & $(3.993)$ \\
\hline \multirow[t]{2}{*}{ number of marriages } & -0.135 & -1.345 & $-1.117^{* *}$ & -1.412 \\
\hline & $(0.228)$ & $(8.318)$ & $(0.467)$ & $(17.779)$ \\
\hline \multirow[t]{2}{*}{ AIDS victims } & $0.053^{* * *}$ & 0.124 & 0.008 & 0.107 \\
\hline & $(0.019)$ & $(1.515)$ & $(0.021)$ & $(1.826)$ \\
\hline \multirow[t]{2}{*}{ age } & $0.145^{* * *}$ & 1.155 & -0.046 & -0.194 \\
\hline & $(0.055)$ & $(3.417)$ & $(0.073)$ & $(8.000)$ \\
\hline \multirow[t]{2}{*}{ age squared } & $-0.001^{* *}$ & -0.002 & 0.000 & 0.001 \\
\hline & $(0.001)$ & $(0.047)$ & $(0.001)$ & $(0.082)$ \\
\hline Constant & $-3.921^{* * *}$ & $2.037^{* * *}$ & $10.616^{* * *}$ & $2.938^{* * *}$ \\
\hline region dummies & Yes & omitted & Yes & omitted \\
\hline time dummies & No & No & Yes & Yes \\
\hline Observations & 3,771 & 952 & 3,771 & 952 \\
\hline Number of respondents & 1,211 & 260 & 1,211 & 260 \\
\hline Hausman-test (chi2) & 69.23 & Hausman- $t$ & st (p-value) & $6.09 \mathrm{e}-08$ \\
\hline
\end{tabular}


Table 7: Logit estimates of determinants of acceptance of condom use with spouse

I estimate a logit model using panel data from 1998-2008. Standard errors are computed by performing 250 bootstrap replications and are indicated in parentheses $\left(* * * \mathrm{p}<0.01,{ }^{* *} \mathrm{p}<0.05,{ }^{*} \mathrm{p}<0.1\right.$ ).

\begin{tabular}{|c|c|c|c|c|}
\hline condom w spouse & (1) Random Effects & (2) Fixed Effects & (3) Time Dummy & (4) Two-Way \\
\hline \multicolumn{5}{|c|}{ Empowerment (personal) } \\
\hline \multirow[t]{2}{*}{ education } & $0.051^{* * *}$ & 0.008 & $0.030^{*}$ & 0.001 \\
\hline & $(0.018)$ & $(0.088)$ & $(0.018)$ & $(0.087)$ \\
\hline \multirow[t]{2}{*}{ low earnings } & 0.161 & -0.026 & -0.034 & -0.027 \\
\hline & $(0.129)$ & $(0.186)$ & $(0.136)$ & $(0.192)$ \\
\hline \multirow[t]{2}{*}{ medium earnings } & 0.170 & -0.086 & -0.030 & -0.073 \\
\hline & $(0.134)$ & $(0.183)$ & $(0.141)$ & $(0.186)$ \\
\hline \multirow[t]{2}{*}{ high earnings } & $0.232^{*}$ & 0.022 & 0.076 & 0.053 \\
\hline & $(0.136)$ & $(0.176)$ & $(0.142)$ & $(0.180)$ \\
\hline \multirow[t]{2}{*}{ language } & 0.048 & -0.145 & -0.102 & -0.203 \\
\hline & $(0.103)$ & $(0.248)$ & $(0.104)$ & $(0.254)$ \\
\hline \multicolumn{5}{|c|}{ Empowerment (interpersonal) } \\
\hline \multirow[t]{2}{*}{ no financial support } & $0.188^{* *}$ & 0.043 & 0.146 & 0.031 \\
\hline & $(0.091)$ & $(0.120)$ & $(0.094)$ & $(0.119)$ \\
\hline \multirow[t]{2}{*}{ violence } & 0.068 & -0.060 & 0.060 & -0.036 \\
\hline & $(0.103)$ & $(0.128)$ & $(0.101)$ & $(0.129)$ \\
\hline \multirow[t]{2}{*}{ infidelity } & -0.032 & -0.012 & $-0.174^{*}$ & -0.035 \\
\hline & $(0.098)$ & $(0.130)$ & $(0.101)$ & $(0.132)$ \\
\hline \multirow[t]{2}{*}{ HIV infected } & $0.191^{*}$ & $0.272^{* *}$ & $0.183^{*}$ & $0.227^{*}$ \\
\hline & $(0.101)$ & $(0.121)$ & $(0.104)$ & $(0.124)$ \\
\hline \multirow[t]{2}{*}{ no family planning } & $0.317^{* * *}$ & $0.314^{* * *}$ & $0.303^{* * *}$ & $0.301^{* *}$ \\
\hline & $(0.101)$ & $(0.122)$ & $(0.101)$ & $(0.124)$ \\
\hline \multirow[t]{2}{*}{ number of wives } & $0.186^{* * *}$ & 0.112 & $0.158^{* * *}$ & 0.090 \\
\hline & $(0.055)$ & $(0.083)$ & $(0.057)$ & $(0.085)$ \\
\hline \multirow[t]{2}{*}{ age at marriage } & -0.013 & -0.005 & -0.008 & -0.004 \\
\hline & $(0.010)$ & $(0.035)$ & $(0.010)$ & $(0.035)$ \\
\hline \multicolumn{5}{|c|}{ Household and background characteristics } \\
\hline \multirow[t]{2}{*}{ relative wealth } & -0.071 & $-0.148^{* *}$ & $-0.087^{*}$ & -0.113 \\
\hline & $(0.051)$ & $(0.070)$ & $(0.053)$ & $(0.071)$ \\
\hline \multirow[t]{2}{*}{ children } & 0.018 & -0.024 & 0.002 & -0.028 \\
\hline & $(0.025)$ & $(0.061)$ & $(0.025)$ & $(0.062)$ \\
\hline \multirow[t]{2}{*}{ number of marriages } & $0.146^{*}$ & -0.268 & 0.037 & -0.187 \\
\hline & $(0.088)$ & $(0.281)$ & $(0.087)$ & $(0.286)$ \\
\hline \multirow[t]{2}{*}{ AIDS victims } & $0.009^{* *}$ & 0.008 & -0.000 & 0.006 \\
\hline & $(0.004)$ & $(0.011)$ & $(0.005)$ & $(0.011)$ \\
\hline \multirow[t]{2}{*}{ age } & 0.007 & $0.217^{* * *}$ & $-0.037^{*}$ & $0.252^{* * *}$ \\
\hline & $(0.023)$ & $(0.053)$ & $(0.021)$ & $(0.088)$ \\
\hline \multirow[t]{2}{*}{ age squared } & -0.000 & $-0.001^{*}$ & 0.000 & -0.001 \\
\hline & $(0.000)$ & $(0.001)$ & $(0.000)$ & $(0.001)$ \\
\hline Constant & $-1.947^{* * *}$ & $-0.828 * * *$ & 0.304 & $-0.813^{* * *}$ \\
\hline region dummies & Yes & omitted & Yes & omitted \\
\hline time dummies & No & No & Yes & Yes \\
\hline Observations & 3,815 & 2,350 & 3,815 & 2,350 \\
\hline Number of respondents & 1,251 & 642 & 1,251 & 642 \\
\hline Hausman-test (chi2) & 92.31 & Hausman-t & st (p-value) & 0 \\
\hline
\end{tabular}




\subsection{Effectiveness of HIV Prevention Strategies}

So far, we have studied determinants of HIV prevention strategies. Needless to say, we would also want to know whether these prevention strategies are effective in the given set-up. Data on HIV infection rates among the MDICP respondents is available from 2004 onwards. Therefore, waves 3,4 , and 5 can be used in order to study the association between HIV infection risk and lagged values of protection modes. Reverse causality could be an issue in this setting. Therefore, the results should be interpreted as correlates rather than as the causal effect of protection modes on HIV risk. Besides the two protection modes studied before (i.e. spousal communication about HIV and acceptance of condom use within marriage), eight other protection methods are included in the regression. Information on the prevalence of these protection modes stems from the MDICP questionnaires as well. Respondents were asked "What do you think are the best ways to protect yourself from getting AIDS?". Since the list was not read to participants, it can be expected that effects of social desirability, i.e. mentioning protection categories that one thinks are preferred by the interviewer, do not play a major role. More than one answer was possible. Summary statistics for the protection categories are listed in Table 8 below, detailed descriptions of the variables can again be found in the appendix. Among the most widely accepted HIV prevention methods we find fidelity which is mentioned by $52.9 \%$ of the respondents. $41.1 \%$ consider it as a good prevention strategy to advice their husband to "take care", a term that means to either be faithful or to use condoms with other partners (Zulu and Chepngeno, 2003). The fact that 30.1\% mention the importance of avoiding transfusions, injections or sharing of razor blades reflects awareness about non-sexual transmission of HIV. Abstinence is quoted by $29.4 \%$ as a prevention method. Altough abstinence is a central feature of the so-called ABC-campaigns (Abstain, Be Faithful, Use Condoms), it is questionable how feasible this prevention method is for married women.

Table 8: Summary Statistics for Protection Methods

\begin{tabular}{lccccc}
\hline Variable & Obs & Mean & Std. Dev. & Min & Max \\
\hline $\begin{array}{l}\text { Dependent variables used } \\
\text { condom analysis }\end{array}$ & & & \\
spousal communication & 5067 & 0.3000 & 0.4583 & 0 & 1 \\
\hline Best ways to prevent AIDS (list & 0.8333 & 0.3728 & 0 & 1 \\
advice spouse & 5106 & 0.4113 & 0.4921 & 0 & 1 \\
condom w other & 5114 & 0.1953 & 0.3965 & 0 & 1 \\
condom w infected & 5090 & 0.0261 & 0.1595 & 0 & 1 \\
no sex w other & 5111 & 0.5285 & 0.4992 & 0 & 1 \\
not many partner & 5092 & 0.0788 & 0.2694 & 0 & 1 \\
no sex w infected & 5090 & 0.0332 & 0.1792 & 0 & 1 \\
no transfusion & 5108 & 0.3007 & 0.4586 & 0 & 1 \\
abstinence & 5148 & 0.2937 & 0.4555 & 0 & 1 \\
\hline
\end{tabular}

Results on the correlation between HIV infection risk and lagged values of different HIV protection modes can be found in Table 9. Spousal communication is significantly associated with lower HIV risk, whereas the results with respect to the acceptance of condom use in marriage are inconclusive. There could be reverse causality at work, as respondents with higher HIV risk might be more likely to use condoms, partly also in order to protect their partners. Nevertheless, there are no grounds on which the effectiveness of condoms in preventing HIV infections can be challenged in general. There are numerous studies showing the effectiveness of condoms as an HIV prevention strategy (for an overview, see e.g. Deuchert, 2007). However, it remains questionable to expect a risk-reducing effect of condom use in this particular setting: The MDICP data studies married women who live in a traditional society that values many children, but associates condom use with infidelity (Reniers, 2008; Zulu and Chepngeno, 2003, p. 
274). In other words, from a public health perspective condoms might be the correct answer, but from a socio-cultural perspective, they are not. Unless perceptions and attitudes change, we should not be surprised to observe insignificant results with respect to the effect of condom use on HIV prevalence rates.

Regarding the acceptance of other protection modes, the effect on HIV infection rates is largely insignificant. It has to be taken into account, though, that we observe self-reported perceptions rather than self-reported behavior. The only statistically significant coefficient can be found with respect to the use of condoms with people who are infected with HIV. The effect is positive which might again be due to reverse causality. In other words, survey participants might indicate this protection mode because they themselves are in a relationship with someone who is infected with HIV - which makes them of course more likely to be infected as well.

The results for the individual coefficients are also reflected by the Wald test of joint significance: Over all coefficients, the Chi-square (12) test statistic is 19.80, which corresponds to a p-value of $7.09 \%$. Therefore, the null that all coefficients are equal to zero can be rejected, although only on the $10 \%$ level. I also run a Wald test for the two protection methods that are at the center of this analysis, i.e. spousal communication and condom use within marriage. Here, the Chi-square (2) test statistic of 3.72 does not allow us to reject the null of joint insignificance on any conventional significance level. As abovementioned, spousal communication is a very common as well as effective strategy of HIV risk reduction among the MDICP survey population. The use of condoms within marriage, however, is not well accepted in the traditional society that the MDICP respondents live in. Therefore the failure to reject the null of the Wald test is not surprising. To sum it up, the results provide support for hypothesis H3, i.e. more widespread acceptance of adequate HIV prevention methods are associated with a decrease in HIV prevalence. However, the hypothesis is only confirmed for HIV-related spousal communication, but not for condom use. In other words, it has to be taken into account that adequacy of prevention methods is not only determined from a medical, but also from a cultural perspective. 
Table 9: Correlates of HIV infection

I estimate a linear probability model using panel data from 2004-2008. HIV prevalence among MDICP respondents is regressed on lagged values of prevention methods (i.e. I use the results from the precedent wave). Robust standard errors are indicated in parentheses $\left(* * * \mathrm{p}<0.01,{ }^{* *} \mathrm{p}<0.05,{ }^{*} \mathrm{p}<0.1\right)$.

\begin{tabular}{|c|c|c|c|c|}
\hline HIV & (1) Random Effects & (2) Fixed Effects & (3) Time Dummy & (4) Two-Way FE \\
\hline \multirow[t]{2}{*}{ condom use w spouse (lag) } & 0.002 & 0.001 & 0.002 & 0.001 \\
\hline & $(0.002)$ & $(0.001)$ & $(0.002)$ & $(0.001)$ \\
\hline \multirow[t]{2}{*}{ spousal communication (lag) } & $-0.017^{*}$ & -0.003 & $-0.020^{*}$ & -0.007 \\
\hline & $(0.010)$ & $(0.003)$ & $(0.010)$ & $(0.005)$ \\
\hline \multirow[t]{2}{*}{ advice spouse (lag) } & 0.005 & 0.004 & 0.004 & 0.003 \\
\hline & $(0.008)$ & $(0.008)$ & $(0.007)$ & $(0.008)$ \\
\hline \multirow[t]{2}{*}{ condom w other (lag) } & -0.007 & -0.005 & -0.007 & -0.006 \\
\hline & $(0.006)$ & $(0.006)$ & $(0.006)$ & $(0.006)$ \\
\hline \multirow[t]{2}{*}{ condom w infected (lag) } & $0.011^{*}$ & 0.004 & $0.010^{*}$ & 0.003 \\
\hline & $(0.006)$ & $(0.003)$ & $(0.006)$ & $(0.003)$ \\
\hline \multirow[t]{2}{*}{ no sex with other (lag) } & 0.010 & 0.009 & 0.006 & 0.006 \\
\hline & $(0.006)$ & $(0.006)$ & $(0.006)$ & $(0.006)$ \\
\hline \multirow[t]{2}{*}{ not many partner (lag) } & 0.000 & 0.001 & -0.002 & -0.000 \\
\hline & $(0.003)$ & $(0.002)$ & $(0.002)$ & $(0.002)$ \\
\hline \multirow[t]{2}{*}{ no sex w infected (lag) } & -0.002 & 0.000 & -0.001 & 0.001 \\
\hline & $(0.003)$ & $(0.002)$ & $(0.003)$ & $(0.002)$ \\
\hline \multirow[t]{2}{*}{ no transfusion (lag) } & -0.004 & -0.002 & -0.009 & -0.007 \\
\hline & $(0.007)$ & $(0.008)$ & $(0.010)$ & $(0.010)$ \\
\hline \multirow[t]{2}{*}{ abstinence (lag) } & 0.004 & 0.004 & 0.004 & 0.004 \\
\hline & $(0.003)$ & $(0.003)$ & $(0.003)$ & $(0.003)$ \\
\hline \multirow[t]{2}{*}{ Constant } & $0.063^{* * *}$ & $0.078^{* * *}$ & $0.074^{* * *}$ & $0.088^{* * *}$ \\
\hline & $(0.017)$ & $(0.003)$ & $(0.019)$ & $(0.009)$ \\
\hline region dummies & Yes & omitted & Yes & omitted \\
\hline time dummies & No & No & Yes & Yes \\
\hline Observations & 1,313 & 1,313 & 1,313 & 1,313 \\
\hline Number of respondents & 836 & 836 & 836 & 836 \\
\hline R2 Within & 0.00787 & 0.00931 & 0.0123 & 0.0138 \\
\hline R2 Between & 0.0238 & 0.00287 & 0.0237 & 0.00411 \\
\hline R2 Overall & 0.0179 & 0.00223 & 0.0178 & 0.00270 \\
\hline Breusch-Pagan (lm) & 338.0 & \multicolumn{2}{|c|}{ Breusch-Pagan (p-value) } & 0 \\
\hline Hausman-test (chi2) & 13.95 & \multicolumn{2}{|c|}{ Hausman-test ( $p$-value) } & 0.175 \\
\hline
\end{tabular}

\section{Conclusions}

Using a panel data set of more than 1,200 married women in three regions in rural Malawi from 1998-2008, this paper shows that adequate HIV prevention strategies are more widely used as women's bargaining power increases. More specifically, the acceptance of condom use within marriage as well as HIV-related spousal communication become more prevalent as women become more empowered. When measuring women's empowerment, I employ a multidimensional approach focusing on both personal (e.g. education and income) and interpersonal aspects (e.g. social status and outside options). Among the proxies used for women's empowerment, own income, knowledge of other local languages and awareness of exit options from marriage are found to play a particularly important role in promoting adequate preventive behaviors. When studying the determinants of spousal communication, personal empowerment is found to be more relevant than interpersonal empowerment, both in terms of size as well as significance of the coefficients. However, when the acceptance of condoms is used as the dependent variable, the proxies for interpersonal empowerment have larger and more significant coefficients than the measures of personal empowerment. This result indicates the importance of employing a multidimensional definition 
of women's empowerment that allows to distinguish between the effects of personal and interpersonal empowerment on HIV prevention efforts. I also conduct Wald tests of joint significance of the coefficients for both the personal as well as the interpersonal dimension of women's empowerment. The null that all coefficients are equal to zero can be rejected for both dimensions of empowerment. In a nutshell, the empirical results provide strong support for hypothesis $\mathrm{H} 1$ and H2, i.e. women's empowerment promotes HIV-related spousal communication as well as the acceptance of condom use within marriage.

The main findings are maintained after individual-specific fixed effects and time dummies are included in order to account for unobserved hetereogeneity. When analyzing the three regions separately, the results remain consistent with the main hypothesis, i.e. women's empowerment significantly promotes HIV prevention. Yet, some effects differ across regions, e.g. the effect of education and own earnings, mainly also because the level of education and earnings is lower in the Southern than in the Northern part of the country. These differences suggest that policy programs ought to take regional differences into account when designing empowerment programs. The results do not change qualitatively when employing non-linear estimation methods, namely random effects logit and conditional fixed effects logit with bootstrapped standard errors.

Further, the correlation between HIV infection rates and lagged values of ten different protection methods is investigated. Spousal communication is associated with significantly lower levels of HIV prevalence, thereby suggesting that this HIV prevention method is not only well-accepted from a cultural point of view, but also effective from a public health perspective. Women who talk with their partners about the risk of HIV and about the measures that they can both take in order to protect each other, are significantly less likely to get infected with HIV. The association between condom use within marriage and HIV prevalence is not statistically significant. This is not surprising, as in rural Malawi condom use is strongly associated with infidelity and therefore not well accepted in the context of marriage (Reniers, 2008; Zulu and Chepngeno, 2003, p. 274). This result is also reflected by the Wald test of joint significance: if all coefficients are jointly assessed, we can reject the null of joint insignificance; if the Wald test is conducted for spousal communication and condom use only, we cannot reject it. To sum it up it can be said that the results provide support for hypothesis H3, i.e. more widespread acceptance of adequate HIV prevention methods is associated with a decrease in HIV prevalence. However, the hypothesis is only confirmed for HIV-related spousal communication, but not for condom use within marriage. In other words, it has to be taken into account that adequacy of prevention methods is not only determined from a medical, but also from a socio-cultural perspective.

The importance of women's empowerment in fighting the spread of HIV is rarely disputed, yet many HIV/AIDS campaigns fail to tackle underlying gender inequalities: According to the World Health Organization, only $52 \%$ of the countries that reported national HIV/AIDS programs to the UN General Assembly provided specific, budgeted support for women-focused HIV/AIDS programs. ${ }^{13}$ The results from my analysis suggest that greater emphasis should be placed on women's empowerment in order to effectively combat the spread of AIDS, particularly in developing countries. Needless to say, women's choices in the context of HIV prevention are also affected by behavioral and socio-economic factors linked to their partners. Following a more comprehensive approach by taking into account the perspective of the spouse and thus interpreting HIV prevention and women's empowerment from a systemic perspective represents an exciting avenue for further research.

\footnotetext{
${ }^{13}$ See also WHO (2012), Gender Inequalities and HIV, http://www.who.int/gender/hiv_aids/en/ .
} 


\section{References}

Angrist, J. And J. Pischke (2009): Mostly Harmless Econometrics - An Empiricist's Companion, Princeton, NJ: Princeton University Press.

Arellano, M. (2003): Panel Data Econometrics, Oxford: Oxford University Press.

Ashraf, N., D. Karlan, and W. Yin (2010): "Female Empowerment: Impact of a Commitment Savings Product in the Philippines," World Development, 38, 333-344.

Beaman, L., R. Chattopadhyay, E. Duflo, R. Pande, and P. Topalova (2009): "Powerful Women: Female Leadership and Gender Bias," Quarterly Journal of Economics, 124, 1497-1540.

Beaman, L., E. Duflo, R. Pande, and P. Topalova (2012): "Female Leadership Raises Aspirations and Educational Attainment for Girls: A Policy Experiment in India," Science, 335, 582-586.

Breusch, T. and A. Pagan (1980): "The Lagrange Multiplier Test and its Applications to Model Specification in Econometrics," Review of Economic Studies, 47, 239-253.

Cameron, C. A. and P. K. Trivedi (2005): Microeconometrics: Methods and Applications, New York: Cambridge University Press.

Coupé, T. (2005): "Bias in Conditional and Unconditional Fixed Effects Logit Estimation: A Correction," Political Analysis, 13, 292-295.

Deuchert, E. (2007): "HIV in Sub Saharan Africa - An Econometric Analysis of HIV Risk Factors," Ph.D. thesis, Albert-Ludwigs-Universität, Freiburg im Breisgau, Germany.

Duflo, E. (2011): "Women's Empowerment and Economic Development," Journal of Economic Literature, forthcoming.

French, J. and B. Raven (1968): "The Bases of Social Power," in Group Dynamics, 3rd. ed., ed. by D. Cartwright and A. Zander, New York: Harper and Row, 259-269.

Greene, W. (2002): "The Bias of the Fixed Effects Estimator in Nonlinear Models," Working Paper, New York University, Department of Economics, Stern School of Business.

Greig, F. and C. Koopman (2003): "Multilevel Analysis of Women's Empowerment and HIV Prevention: Quantitative Survey Results from a Preliminary Study in Botswana," AIDS and Behavior, 7, $195-208$.

Gutiérrez, L., H. Оh, And M. Gillmore (2000): "Towards an Understanding of (Em)Power(Ment) for HIV/AIDS Prevention with Adolescent Women," Sex Roles, 42, 581-611.

Hausman, J. (1978): "Specification Tests in Econometrics," Econometrica, 46, 1251-1271.

Helleringer, S. and H. Kohler (2005): "Social Networks, Perceptions of Risk, and Changing Attitudes Towards HIV/AIDS: New Evidence from a Longitudinal Study Using Fixed-Effects Analysis," Population Studies, 59, 265-282.

Hirschman, A. (1970): Exit, Voice, and Loyalty: Responses to Decline in Firms, Organizations, and States, Cambridge, MA: Harvard University Press.

(1995): A Propensity to Self-Subversion, Cambridge, MA: Harvard University Press. 
Kaler, A. (2003): "My Girlfriends Could Fill A Yanu-Yanu Bus': Rural Malawian Men's Claims About Their Own Serostatus," Demographic Research, Special Collection 1, 349-372.

Kim, J., P. Pronyk, T. Barnett, and C. Watts (2008): "Exploring the Role of Economic Empowerment in HIV Prevention," AIDS, 22, 57-71.

Lancaster, T. (2000): "The Incidental Parameter Problem Since 1948," Journal of Econometrics, 95, $391-413$.

Noar, S., K. Carlyle, And C. Cole (2006): "Why Communication is Crucial: Meta-Analysis of the Relationship Between Safer Sexual Communication and Condom Use," Journal of Health Communication, 11, 365-390.

Opuni, M., A. Peterman, and D. Bishai (2011): "Inequality in Prime-Age Adult Deaths in a High Aids Mortality Setting: Does the Measure of Economic Status Matter?" Health Economics, 20, 12981311.

Orfei, A. (2010): "The Impact of Female Empowerment on Male Extramarital Sexual Behavior: Evidence from West Africa," Working Paper, University of Maryland.

Philipson, T. And R. Posner (1993): Private Choices and Public Health - The AIDS Epidemic in an Economic Perspective, Cambridge, MA: Harvard University Press.

Pronyk, P., J. Kim, T. Abramsky, G. Phetla, J. Hargreaves, L. Morison, C. Watts, J. Busza, And J. Porter (2008): "A Combined Microfinance and Training Intervention can Reduce HIV Risk Behaviour in Young Female Participants," AIDS, 22, 1659-1664.

Reniers, G. (2008): "Marital Strategies for Regulating Exposure to HIV," Demography, 45, 417-438.

Reniers, G. And R. Tfaily (2008): "Polygyny and HIV in Malawi," Demographic Research, 19, 18111830.

(2010): "An Inquiry into the Mechanisms Linking Polygyny, Partnership Concurrency and HIV Transmission in Sub-Saharan Africa," Working Paper, Princeton University, Office of Population Research, OPR-2010-03.

Rusbult, C. And I. Zembrodt (1983): "Responses to Dissatisfaction in Romantic Involvements: A Multidimensional Scaling Analysis," Journal of Experimental Social Psychology, 19, 274-293.

Rusbult, C., I. Zembrodt, and L. Gunn (1982): "Exit, Voice, Loyalty, and Neglect: Responses to Dissatisfaction in Romantic Involvements," Journal of Personality and Social Psychology, 43, 12301242.

Schatz, E. (2005): "'Take your mat and go!': Rural Malawian Women's Strategies in the HIV/AIDS Era," Culture, Health IES Sexuality, 7, 479-492.

Swidler, A. (2007): "Ties of Dependence: AIDS and Transactional Sex in Rural Malawi," Studies in Family Planning, 38, 147-162.

Thornton, R. (2008): "The Demand for, and Impact of, Learning HIV Status," American Economic Review, 98, 1829-1863.

TÜrmen, T. (2003): "Gender and HIV/AIDS," International Journal of Gynecology and Obstetrics, 82, $411-418$ 
UNAIDS (2010): Global Report: UNAIDS Report on the Global AIDS Epidemic 2010, Geneva, Switzerland: United Nations, Joint United Nations Programme on HIV/AIDS.

Van der Straten, A., R. King, O. Grinstead, E. Vittinghoff, A. Seruflira, and S. Allen (1998): "Sexual Coercion, Physical Violence, and HIV Infection Among Women in Steady Relationships in Kigali, Rwanda," AIDS and Behavior, 2, 61-73.

Watkins, S., E. Zulu, H. Kohler, and J. Behrman (2003): "Introduction to: Social Interactions and HIV/AIDS in Rural Africa," Demographic Research, Special Collection 1, 1-30.

WoJcicki, J. and J. Malala (2001): "Condom Use, Power and HIV/AIDS Risk: Sex-Workers Bargain for Survival in Hillbrow/Joubert Park/ Berea, Johannesburg," Social Science IE3 Medicine, 53, 99-121.

Wooldridge, J. (2002): Econometric Analysis of Cross Section and Panel Data, Cambridge, MA: MIT Press.

World Health Organization, Department of Gender, W. and Health (2009): Integrating Gender into HIV/AIDS Programmes in the Health Sector, Geneva, Switzerland: World Health Organization.

Zulu, E. And G. Chepngeno (2003): "Spousal Communication abouth the Risk of Contracting HIV/AIDS in rural Malawi," Demographic Research, Special Collection 1, 248-275. 


\section{Appendix}

Table 10: Variable descriptions

\begin{tabular}{lll}
\hline Variable Name & Description & Type \\
\hline HIV prevalence and protection strategies & Dummy \\
HIV & Result from HIV test (free of charge, randomly assigned) & Dummy \\
spousal communication & Respondent has talked with spouse about risk of HIV infection & Dummy \\
condom use w spouse & Respondent considers condom use with spouse acceptable & Continuous \\
\hline $\begin{array}{l}\text { Empowerment (personal) } \\
\text { education }\end{array}$ & Years of formal education that respondent has had & Continuous \\
earnings & Own earnings generated during last year. For 2004, this value & \\
& has been interpolated by using the previous and the consecutive & \\
& survey waves. One survey participant was dropped from the & \\
& sample because her earnings were either missing or & Dummy \\
no earnings & unrealistically high, i.e. over 8,000 USD a year. & Dummy \\
low earnings & Did not generate any personal earnings during last year & \\
Respondent was in lowest income group last year. For positive & Dummy \\
high earnings & income values, 3 quantiles were identified (low, medium, high). & Dummy \\
language & Respondent was in medium income group last year & Continuous \\
\hline
\end{tabular}

Empowerment (interpersonal)

Acceptable reasons to leave husband

violence

Husband beats her frequently

Dummy

infidelity

Husband is unfaithful

Dummy

HIV infected

Husband is infected with HIV

Dummy

no family planning

Husband does not allow family planning

Dummy

polygamy

Wife of polygamous husband

Dummy

number of wives

Number of co-wives

Dummy

age at marriage

Age of respondent at current marriage. 7 observations are

Continuous

deleted as respondents indicate 70 or older.

Household and background characteristics

relative wealth

Relative wealth of household (according to interviewer)

Continuous

children

Number of living children. Respondents with more than 25

Ordinal

children are dropped from the data. Overstating the number of

children might reflect a different cultural understanding of family

ties, i.e. nieces and nephews will be considered daughters and

sons if (financial) responsibility is taken for them (Swidler, 2007).

number of marriages

Number of times respondent has been married in lifetime

Continuous

AIDS victims

Number of AIDS victims known to respondent. One observation

Continuous was dropped as participant claims to know 200 (which is astonishingly high and also more than 30 times higher than the value that the same respondent indicated in precedent waves).

\begin{tabular}{lll} 
age & Age in years & Continuous \\
central & Lives in Central region (Mchinji district) & Dummy \\
north & Lives in Northern region (Rumphi district) & Dummy \\
south & Lives in Southern region (Balaka district) & Dummy \\
\hline Best ways to prevent & AIDS (list was not read to participants, more than 1 answer possible) & \\
advice spouse & Advice spouse to "take care" (e.g. be faithful, use condoms) & Dummy \\
condom w other & Use condoms with all other partners except spouse & Dummy \\
condom w infected & Use condoms with people you think might be infected & Dummy \\
no sex w other & Avoid sex with any partners except spouse & Dummy \\
not many partners & Avoid sex with many partners & Dummy \\
no sex w infected & Avoid sex with people you think might be infected & Dummy \\
no transfusion & Avoid transfusions / injections / sharing razor blades & Dummy \\
abstinence & Abstinence & Dummy \\
\hline
\end{tabular}


Table 11: Sample composition over time

The table shows changes in the MDICP sample composition from 1998-2008. For my analysis, I only use the 1998 original sample.

\begin{tabular}{lccccc|c}
\hline & \multicolumn{7}{c}{ Year } \\
\hline 1998 original sample & 1998 & 2001 & 2004 & 2006 & 2008 & Total \\
New spouse 2001 & 0 & 237 & 171 & 149 & 113 & 670 \\
New spouse 2004 & 0 & 0 & 0 & 9 & 0 & 9 \\
New spouse 2006 & 0 & 0 & 0 & 276 & 178 & 454 \\
New spouse 2008 & 0 & 0 & 0 & 0 & 207 & 207 \\
2004 adolescent & 0 & 0 & 340 & 334 & 282 & 956 \\
2008 Parent & 0 & 0 & 0 & 0 & 166 & 166 \\
\hline
\end{tabular}

Table 12: Descriptive statistics (by region)

\begin{tabular}{lcccccc}
\hline & \multicolumn{2}{c}{ Central } & \multicolumn{2}{c}{ North } & \multicolumn{2}{c}{ South } \\
\hline HIV & Mean & Std. Err. & Mean & Std. Err. & Mean & Std. Err. \\
spousal communication & 0.0477 & 0.2134 & 0.0435 & 0.2041 & 0.0960 & 0.2948 \\
condom use w spouse & 0.8520 & 0.3552 & 0.8790 & 0.3262 & 0.7670 & 0.4229 \\
education & 3.2254 & 2.7001 & 6.0796 & 2.1812 & 1.6939 & 2.3319 \\
earnings & 14705.69 & 38113.65 & 16736.83 & 43278.61 & 6806.99 & 15319.91 \\
no earnings & 0.1659 & 0.3721 & 0.1353 & 0.3421 & 0.1905 & 0.3928 \\
low earnings & 0.2359 & 0.4247 & 0.2052 & 0.4040 & 0.3370 & 0.4728 \\
medium earnings & 0.2691 & 0.4436 & 0.2985 & 0.4578 & 0.2941 & 0.4557 \\
high earnings & 0.3292 & 0.4700 & 0.3609 & 0.4804 & 0.1785 & 0.3830 \\
language & 0.4032 & 0.4907 & 0.8645 & 0.3424 & 0.8206 & 0.3838 \\
no financial support & 0.4083 & 0.4917 & 0.2440 & 0.4296 & 0.4561 & 0.4982 \\
violence & 0.7412 & 0.4381 & 0.7253 & 0.4465 & 0.7675 & 0.4226 \\
infidelity & 0.8015 & 0.3990 & 0.6900 & 0.4626 & 0.8165 & 0.3872 \\
HIV infected & 0.1809 & 0.3850 & 0.1555 & 0.3625 & 0.3728 & 0.4837 \\
no family planning & 0.2373 & 0.4255 & 0.1328 & 0.3395 & 0.3547 & 0.4786 \\
polygamy & 0.2269 & 0.4190 & 0.3384 & 0.4733 & 0.2586 & 0.4380 \\
number of wives & 0.2943 & 0.6723 & 0.4697 & 0.8141 & 0.3137 & 0.6122 \\
age at marriage & 19.5306 & 6.7574 & 19.8552 & 6.2538 & 21.1339 & 8.6387 \\
\hline
\end{tabular}


Table 14: Predicted values for spousal communication (1998-2008)

The table shows predicted values for spousal communication. The term "fitted value" refers to the linear prediction, i.e. $a+b x_{i t}$, whereas the term "predicted values $u_{i}$ " refers to the fixed- or random-error component in the estimated equation, respectively.

\begin{tabular}{|c|c|c|c|c|c|c|}
\hline & Spousal communication & Obs & Mean & Std.Dev. & Min & Max \\
\hline \multirow{3}{*}{ Random Effects } & Actual values & 5320 & 0.8333 & 0.3728 & 0.0000 & 1.0000 \\
\hline & Fitted values & 3854 & 0.8740 & 0.1176 & 0.3744 & 1.2675 \\
\hline & Predicted values $u_{i}$ & 3771 & 0.0041 & 0.1567 & -0.8636 & 0.2927 \\
\hline \multirow{2}{*}{ Fixed Effects } & Fitted values & 3854 & 0.8788 & 0.3180 & 0.1975 & 2.7270 \\
\hline & Predicted values $u_{i}$ & 3771 & 0.0000 & 0.3966 & -2.2708 & 0.7717 \\
\hline \multirow{2}{*}{ Time Dummies } & Fitted values & 3854 & 0.8762 & 0.1264 & 0.5075 & 1.1543 \\
\hline & Predicted values $u_{i}$ & 3771 & 0.0030 & 0.1464 & -0.7813 & 0.2358 \\
\hline \multirow{2}{*}{ Two-Way FE } & Fitted values & 3854 & 0.8796 & 0.1506 & 0.3053 & 1.2098 \\
\hline & Predicted values $u_{i}$ & 3771 & 0.0000 & 0.2426 & -1.1349 & 0.6947 \\
\hline
\end{tabular}

Table 15: Predicted values for acceptance of condom use (1998-2008)

The table shows predicted values for spousal communication. The term "fitted value" refers to the linear prediction, i.e. $a+b x_{i t}$, whereas the term "predicted values $u_{i}$ " refers to the fixed- or random-error component in the estimated equation, respectively.

\begin{tabular}{llccccc}
\hline & Spousal communication & Obs & Mean & Std.Dev. & Min & Max \\
\hline \multirow{4}{*}{ Random Effects } & Actual values & 5067 & 0.3000 & 0.4583 & 0.0000 & 1.0000 \\
& Fitted values & 3854 & 0.3191 & 0.1039 & 0.0881 & 0.6930 \\
& Predicted values $u_{i}$ & 3815 & 0.0002 & 0.0645 & -0.1356 & 0.2071 \\
& Fitted values & 3854 & 0.3208 & 0.2439 & -0.2792 & 1.1808 \\
\multirow{2}{*}{ Timed Effects Dummies } & Predicted values $u_{i}$ & 3815 & 0.0000 & 0.3759 & -1.0695 & 1.1630 \\
& Fitted values & 3854 & 0.3191 & 0.1261 & -0.0195 & 0.6914 \\
& Predicted values $u_{i}$ & 3815 & 0.0001 & 0.0568 & -0.1199 & 0.1833 \\
& Fitted values & 3854 & 0.3225 & 0.4115 & -0.5330 & 2.1066 \\
& Predicted values $u_{i}$ & 3815 & 0.0000 & 0.5027 & -1.9226 & 1.3587 \\
\hline
\end{tabular}

Table 16: T-tests of difference in means between individual-specific effects from 1998-2001 and 2004-2008 (spousal communication)

The table shows summary results of two-sided t-tests of difference in means between the estimated individual-specific effects from 1998-2001 and from 2004-2008 for HIV-related spousal communication.

\begin{tabular}{lcccccc}
\hline \multirow{2}{*}{ Spousal communication } & \multicolumn{3}{c}{ Tndividual-specific effect } & \multicolumn{2}{c}{ T-test } \\
\hline Random effects & $1998-2001$ & -0.0041 & 0.0080 & 838 & t-stat & -0.9857 \\
& $2004-2008$ & 0.0042 & 0.0051 & 838 & p-value & 0.3246 \\
Fixed effects & $1998-2001$ & -0.0257 & 0.0279 & 838 & t-stat & -1.0727 \\
& $2004-2008$ & 0.0025 & 0.0071 & 838 & p-value & 0.2837 \\
RE with time dummy & $1998-2001$ & -0.0034 & 0.0079 & 838 & t-stat & -0.9624 \\
& $2004-2008$ & 0.0047 & 0.0051 & 838 & p-value & 0.3361 \\
FE with time dummy & $1998-2001$ & -0.0257 & 0.0279 & 838 & t-stat & -1.0718 \\
& $2004-2008$ & 0.0023 & 0.0073 & 838 & p-value & 0.2841 \\
\hline
\end{tabular}




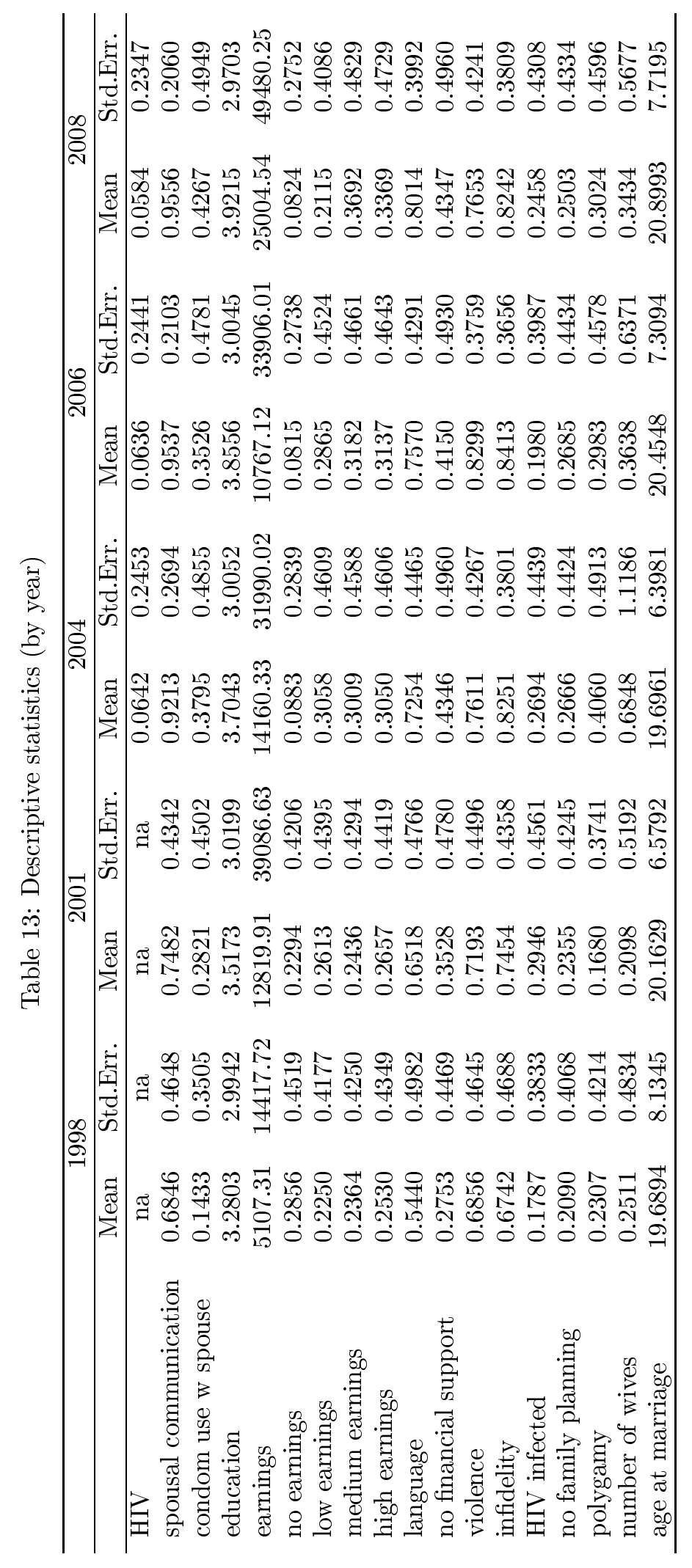


Table 17: T-tests of difference in means between individual-specific effects from 1998-2001 and 2004-2008 (acceptance of condom use)

The table shows summary results of two-sided t-tests of difference in means between the estimated individual-specific effects from 1998-2001 and from 2004-2008 for the acceptance of condom use within marriage.

\begin{tabular}{|c|c|c|c|c|c|c|}
\hline \multirow{3}{*}{$\begin{array}{l}\text { Condom use w spouse } \\
\text { Random effects }\end{array}$} & \multicolumn{6}{|c|}{ Individual-specific effect } \\
\hline & \multirow{2}{*}{$\frac{\text { Time period }}{1998-2001}$} & \multirow{2}{*}{$\frac{\text { Mean }}{0.0009}$} & \multirow{2}{*}{$\frac{\text { Std. Error }}{0.0023}$} & \multirow{2}{*}{$\frac{\text { Obs }}{852}$} & \multicolumn{2}{|c|}{ T-test } \\
\hline & & & & & t-stat & 0.2052 \\
\hline & 2004-2008 & 0.0003 & 0.0024 & 852 & p-value & 0.8374 \\
\hline \multirow[t]{2}{*}{ Fixed effects } & $1998-2001$ & 0.0158 & 0.0189 & 852 & t-stat & 1.4987 \\
\hline & 2004-2008 & -0.0113 & 0.0161 & 852 & $\mathrm{p}$-value & 0.1343 \\
\hline \multirow[t]{2}{*}{ RE with time dummy } & $1998-2001$ & 0.0010 & 0.0023 & 852 & t-stat & 0.1097 \\
\hline & $2004-2008$ & 0.0006 & 0.0024 & 852 & p-value & 0.9127 \\
\hline \multirow[t]{2}{*}{ FE with time dummy } & $1998-2001$ & 0.0158 & 0.0189 & 852 & t-stat & 1.4860 \\
\hline & $2004-2008$ & -0.0112 & 0.0157 & 852 & p-value & 0.1377 \\
\hline
\end{tabular}


Table 18: Determinants of spousal communication about HIV (Central Region)

I estimate a linear probability model using panel data from 1998-2008. Robust standard errors are indicated in parentheses $\left(* * * \mathrm{p}<0.01,{ }^{* *} \mathrm{p}<0.05,{ }^{*} \mathrm{p}<0.1\right)$.

\begin{tabular}{|c|c|c|c|c|}
\hline \multirow{2}{*}{ spousal communication } & \multicolumn{4}{|c|}{ Central } \\
\hline & (1) Random Effects & (2) Fixed Effects & (3) Time Dummy & (4) Two-Way FE \\
\hline \multicolumn{5}{|c|}{ Empowerment (personal) } \\
\hline \multirow[t]{2}{*}{ education } & $0.013^{* * *}$ & -0.002 & 0.006 & -0.003 \\
\hline & $(0.004)$ & $(0.012)$ & $(0.004)$ & $(0.012)$ \\
\hline \multirow[t]{2}{*}{ low earnings } & 0.049 & 0.043 & 0.016 & 0.034 \\
\hline & $(0.033)$ & $(0.036)$ & $(0.032)$ & $(0.036)$ \\
\hline \multirow[t]{2}{*}{ medium earnings } & $0.086^{* * *}$ & $0.065^{*}$ & $0.050 *$ & $0.058^{*}$ \\
\hline & $(0.030)$ & $(0.033)$ & $(0.029)$ & $(0.034)$ \\
\hline \multirow[t]{2}{*}{ high earnings } & $0.102^{* * *}$ & $0.076^{* *}$ & $0.063^{* *}$ & $0.067 * *$ \\
\hline & $(0.029)$ & $(0.032)$ & $(0.028)$ & $(0.032)$ \\
\hline \multirow[t]{2}{*}{ language } & $0.049 * *$ & 0.064 & 0.017 & 0.042 \\
\hline & $(0.024)$ & $(0.056)$ & $(0.023)$ & $(0.056)$ \\
\hline \multicolumn{5}{|c|}{ Empowerment (interpersonal) } \\
\hline \multirow[t]{2}{*}{ no financial support } & 0.023 & -0.005 & 0.003 & -0.008 \\
\hline & $(0.018)$ & $(0.020)$ & $(0.018)$ & $(0.020)$ \\
\hline \multirow[t]{2}{*}{ violence } & 0.021 & 0.024 & 0.028 & 0.030 \\
\hline & $(0.021)$ & $(0.021)$ & $(0.020)$ & $(0.021)$ \\
\hline \multirow[t]{2}{*}{ infidelity } & 0.028 & 0.011 & 0.015 & 0.005 \\
\hline & $(0.023)$ & $(0.024)$ & $(0.022)$ & $(0.024)$ \\
\hline \multirow[t]{2}{*}{ HIV infected } & 0.012 & 0.026 & 0.009 & 0.017 \\
\hline & $(0.019)$ & $(0.020)$ & $(0.019)$ & $(0.021)$ \\
\hline \multirow[t]{2}{*}{ no family planning } & 0.013 & 0.015 & 0.010 & 0.011 \\
\hline & $(0.018)$ & $(0.019)$ & $(0.018)$ & $(0.019)$ \\
\hline \multirow[t]{2}{*}{ number of wives } & $0.019^{* *}$ & $0.017^{*}$ & -0.002 & 0.002 \\
\hline & $(0.008)$ & $(0.010)$ & $(0.007)$ & $(0.010)$ \\
\hline \multirow[t]{2}{*}{ age at marriage } & $-0.013^{* * *}$ & $-0.030 * * *$ & $-0.010^{* *}$ & $-0.030 * * *$ \\
\hline & $(0.004)$ & $(0.011)$ & $(0.004)$ & $(0.011)$ \\
\hline \multicolumn{5}{|c|}{ Household and background characteristics } \\
\hline \multirow[t]{2}{*}{ relativ wealth } & -0.006 & -0.012 & 0.003 & -0.000 \\
\hline & $(0.009)$ & $(0.011)$ & $(0.009)$ & $(0.011)$ \\
\hline \multirow[t]{2}{*}{ children } & $0.017^{* * *}$ & 0.004 & $0.012 * *$ & 0.007 \\
\hline & $(0.006)$ & $(0.011)$ & $(0.006)$ & $(0.011)$ \\
\hline \multirow[t]{2}{*}{ number of marriages } & $0.046^{*}$ & $0.241^{* * *}$ & 0.024 & $0.231^{* *}$ \\
\hline & $(0.028)$ & $(0.087)$ & $(0.028)$ & $(0.090)$ \\
\hline \multirow[t]{2}{*}{ AIDS victims } & $0.003^{* *}$ & 0.000 & -0.000 & -0.001 \\
\hline & $(0.001)$ & $(0.002)$ & $(0.001)$ & $(0.002)$ \\
\hline age & $0.011^{* *}$ & 0.015 & -0.002 & -0.022 \\
\hline & $(0.006)$ & $(0.012)$ & $(0.005)$ & $(0.014)$ \\
\hline age squared & -0.000 & 0.000 & 0.000 & 0.000 \\
\hline & $(0.000)$ & $(0.000)$ & $(0.000)$ & $(0.000)$ \\
\hline Constant & $0.534^{* * *}$ & 0.356 & $1.013^{* * *}$ & $1.654^{* * *}$ \\
\hline & $(0.110)$ & $(0.243)$ & $(0.120)$ & $(0.322)$ \\
\hline time dummies & No & No & Yes & Yes \\
\hline Observations & 1,398 & 1,398 & 1,398 & 1,398 \\
\hline Number of respondents & 459 & 459 & 459 & 459 \\
\hline R2 Within & 0.132 & 0.182 & 0.185 & 0.204 \\
\hline R2 Between & 0.0544 & 0.000119 & 0.0892 & 0.0244 \\
\hline R2 Overall & 0.0656 & 0.00308 & 0.126 & 0.0543 \\
\hline Breusch-Pagan (lm) & 60.03 & Breusch-Pa & an (p-value) & 0 \\
\hline Hausman-test (chi2) & 94.36 & Hausman- & st (p-value) & 0 \\
\hline
\end{tabular}


Table 19: Determinants of spousal communication about HIV (Northern Region)

I estimate a linear probability model using panel data from 1998-2008. Robust standard errors are indicated in parentheses $\left(* * * \mathrm{p}<0.01,{ }^{* *} \mathrm{p}<0.05,{ }^{*} \mathrm{p}<0.1\right)$.

\begin{tabular}{|c|c|c|c|c|}
\hline \multirow{2}{*}{ spousal communication } & \multicolumn{4}{|c|}{ North } \\
\hline & (1) Random Effects & (2) Fixed Effects & (3) Time Dummy & (4) Two-Way FE \\
\hline \multicolumn{5}{|c|}{ Empowerment (personal) } \\
\hline \multirow[t]{2}{*}{ education } & $0.012^{* *}$ & 0.009 & 0.007 & 0.004 \\
\hline & $(0.005)$ & $(0.019)$ & $(0.005)$ & $(0.019)$ \\
\hline \multirow[t]{2}{*}{ low earnings } & 0.009 & 0.011 & -0.034 & -0.009 \\
\hline & $(0.029)$ & $(0.032)$ & $(0.029)$ & $(0.032)$ \\
\hline \multirow[t]{2}{*}{ medium earnings } & 0.031 & 0.035 & -0.008 & 0.016 \\
\hline & $(0.029)$ & $(0.031)$ & $(0.029)$ & $(0.032)$ \\
\hline \multirow[t]{2}{*}{ high earnings } & -0.002 & 0.001 & -0.022 & -0.018 \\
\hline & $(0.029)$ & $(0.031)$ & $(0.029)$ & $(0.032)$ \\
\hline \multirow[t]{2}{*}{ language } & $0.097 * *$ & 0.008 & 0.045 & -0.000 \\
\hline & $(0.038)$ & $(0.044)$ & $(0.037)$ & $(0.045)$ \\
\hline \multicolumn{5}{|c|}{ Empowerment (interpersonal) } \\
\hline \multirow[t]{2}{*}{ no financial support } & -0.028 & -0.003 & -0.019 & -0.007 \\
\hline & $(0.018)$ & $(0.017)$ & $(0.017)$ & $(0.017)$ \\
\hline \multirow[t]{2}{*}{ violence } & $0.033^{*}$ & 0.023 & 0.025 & 0.020 \\
\hline & $(0.019)$ & $(0.019)$ & $(0.019)$ & $(0.019)$ \\
\hline \multirow[t]{2}{*}{ infidelity } & $0.047 * *$ & 0.026 & 0.014 & 0.016 \\
\hline & $(0.020)$ & $(0.021)$ & $(0.019)$ & $(0.021)$ \\
\hline \multirow[t]{2}{*}{ HIV infected } & 0.022 & 0.035 & 0.008 & 0.028 \\
\hline & $(0.021)$ & $(0.023)$ & $(0.020)$ & $(0.023)$ \\
\hline \multirow[t]{2}{*}{ no family planning } & -0.006 & -0.023 & -0.008 & -0.015 \\
\hline & $(0.019)$ & $(0.020)$ & $(0.018)$ & $(0.019)$ \\
\hline \multirow[t]{2}{*}{ number of wives } & 0.003 & 0.007 & -0.008 & -0.009 \\
\hline & $(0.007)$ & $(0.010)$ & $(0.008)$ & $(0.011)$ \\
\hline \multirow[t]{2}{*}{ age at marriage } & $-0.010^{* *}$ & 0.002 & -0.006 & 0.002 \\
\hline & $(0.004)$ & $(0.037)$ & $(0.004)$ & $(0.037)$ \\
\hline \multicolumn{5}{|c|}{ Household and background characteristics } \\
\hline \multirow[t]{2}{*}{ relative wealth } & 0.008 & -0.002 & 0.014 & 0.008 \\
\hline & $(0.012)$ & $(0.013)$ & $(0.011)$ & $(0.013)$ \\
\hline \multirow[t]{2}{*}{ children } & 0.012 & -0.009 & $0.014^{*}$ & -0.009 \\
\hline & $(0.009)$ & $(0.017)$ & $(0.008)$ & $(0.017)$ \\
\hline \multirow[t]{2}{*}{ number of marriages } & 0.012 & 0.035 & -0.014 & 0.041 \\
\hline & $(0.038)$ & $(0.130)$ & $(0.037)$ & $(0.134)$ \\
\hline \multirow[t]{2}{*}{ AIDS victims } & $0.002^{* *}$ & -0.000 & -0.001 & -0.000 \\
\hline & $(0.001)$ & $(0.002)$ & $(0.001)$ & $(0.002)$ \\
\hline age & 0.012 & $0.040^{* *}$ & -0.009 & 0.010 \\
\hline & $(0.008)$ & $(0.016)$ & $(0.008)$ & $(0.017)$ \\
\hline age squared & -0.000 & -0.000 & 0.000 & -0.000 \\
\hline & $(0.000)$ & $(0.000)$ & $(0.000)$ & $(0.000)$ \\
\hline Constant & $0.470 * * *$ & -0.415 & $1.137^{* * *}$ & 0.624 \\
\hline & $(0.150)$ & $(0.737)$ & $(0.161)$ & $(0.770)$ \\
\hline time dummies & No & No & Yes & Yes \\
\hline Observations & 1,314 & 1,314 & 1,314 & 1,314 \\
\hline Number of respondents & 385 & 385 & 385 & 385 \\
\hline R2 Within & 0.117 & 0.159 & 0.178 & 0.185 \\
\hline R2 Between & 0.0436 & 0.0102 & 0.126 & 0.00131 \\
\hline R2 Overall & 0.0551 & 0.00183 & 0.143 & 0.0600 \\
\hline Breusch-Pagan (lm) & 39.95 & Breusch-Pa & an (p-value) & $1.30 \mathrm{e}-10$ \\
\hline Hausman-test (chi2) & 95.82 & Hausman- $t$ & st (p-value) & 0 \\
\hline
\end{tabular}


Table 20: Determinants of spousal communication about HIV (Southern Region)

I estimate a linear probability model using panel data from 1998-2008. Robust standard errors are indicated in parentheses $\left(* * * \mathrm{p}<0.01,{ }^{* *} \mathrm{p}<0.05,{ }^{*} \mathrm{p}<0.1\right)$.

\begin{tabular}{|c|c|c|c|c|}
\hline \multirow{2}{*}{ spousal communication } & \multicolumn{4}{|c|}{ South } \\
\hline & (1) Random Effects & (2) Fixed Effects & (3) Time Dummy & (4) Two-Way FE \\
\hline \multicolumn{5}{|c|}{ Empowerment (personal) } \\
\hline \multirow[t]{2}{*}{ education } & $0.020 * * *$ & -0.001 & 0.006 & -0.009 \\
\hline & $(0.007)$ & $(0.023)$ & $(0.006)$ & $(0.023)$ \\
\hline \multirow[t]{2}{*}{ low earnings } & 0.056 & 0.052 & 0.015 & 0.031 \\
\hline & $(0.039)$ & $(0.040)$ & $(0.036)$ & $(0.040)$ \\
\hline \multirow[t]{2}{*}{ medium earnings } & $0.085^{* *}$ & 0.020 & 0.024 & 0.018 \\
\hline & $(0.037)$ & $(0.040)$ & $(0.036)$ & $(0.040)$ \\
\hline \multirow[t]{2}{*}{ high earnings } & 0.070 & -0.009 & 0.007 & -0.005 \\
\hline & $(0.043)$ & $(0.046)$ & $(0.040)$ & $(0.045)$ \\
\hline \multirow[t]{2}{*}{ language } & $0.199^{* * *}$ & 0.099 & $0.109 * *$ & 0.083 \\
\hline & $(0.050)$ & $(0.063)$ & $(0.052)$ & $(0.063)$ \\
\hline \multicolumn{5}{|c|}{ Empowerment (interpersonal) } \\
\hline \multirow[t]{2}{*}{ no financial support } & 0.021 & -0.005 & -0.014 & -0.015 \\
\hline & $(0.024)$ & $(0.025)$ & $(0.022)$ & $(0.025)$ \\
\hline \multirow[t]{2}{*}{ violence } & 0.017 & 0.015 & 0.011 & 0.010 \\
\hline & $(0.032)$ & $(0.033)$ & $(0.030)$ & $(0.033)$ \\
\hline \multirow[t]{2}{*}{ infidelity } & $0.076^{* *}$ & 0.044 & 0.034 & 0.037 \\
\hline & $(0.034)$ & $(0.037)$ & $(0.034)$ & $(0.037)$ \\
\hline \multirow[t]{2}{*}{ HIV infected } & -0.020 & -0.009 & -0.006 & -0.003 \\
\hline & $(0.022)$ & $(0.023)$ & $(0.021)$ & $(0.023)$ \\
\hline \multirow[t]{2}{*}{ no family planning } & $0.056^{* * *}$ & $0.054^{* * *}$ & $0.053^{* * *}$ & $0.044^{* *}$ \\
\hline & $(0.019)$ & $(0.020)$ & $(0.019)$ & $(0.020)$ \\
\hline \multirow[t]{2}{*}{ number of wives } & 0.006 & -0.012 & -0.024 & -0.032 \\
\hline & $(0.019)$ & $(0.021)$ & $(0.017)$ & $(0.021)$ \\
\hline \multirow[t]{2}{*}{ age at marriage } & -0.003 & -0.004 & 0.000 & -0.001 \\
\hline & $(0.004)$ & $(0.012)$ & $(0.003)$ & $(0.012)$ \\
\hline \multicolumn{5}{|c|}{ Household and background characteristics } \\
\hline \multirow[t]{2}{*}{ relative wealth } & $0.023^{*}$ & 0.006 & 0.006 & 0.007 \\
\hline & $(0.014)$ & $(0.014)$ & $(0.013)$ & $(0.014)$ \\
\hline \multirow[t]{2}{*}{ children } & $0.025^{* * *}$ & 0.019 & $0.015^{* *}$ & 0.020 \\
\hline & $(0.008)$ & $(0.015)$ & $(0.007)$ & $(0.015)$ \\
\hline \multirow[t]{2}{*}{ number of marriages } & -0.030 & -0.048 & $-0.064^{* *}$ & -0.068 \\
\hline & $(0.026)$ & $(0.061)$ & $(0.025)$ & $(0.060)$ \\
\hline \multirow[t]{2}{*}{ AIDS victims } & 0.002 & $-0.005^{*}$ & -0.001 & -0.004 \\
\hline & $(0.002)$ & $(0.003)$ & $(0.002)$ & $(0.003)$ \\
\hline age & 0.011 & 0.016 & -0.006 & $-0.039 * *$ \\
\hline & $(0.007)$ & $(0.017)$ & $(0.007)$ & $(0.018)$ \\
\hline age squared & -0.000 & 0.000 & 0.000 & 0.000 \\
\hline & $(0.000)$ & $(0.000)$ & $(0.000)$ & $(0.000)$ \\
\hline Constant & 0.121 & -0.288 & $0.962^{* * *}$ & $1.861^{* * *}$ \\
\hline & $(0.146)$ & $(0.358)$ & $(0.168)$ & $(0.442)$ \\
\hline time dummies & No & No & Yes & Yes \\
\hline Observations & 1,059 & 1,059 & 1,059 & 1,059 \\
\hline Number of respondents & 367 & 367 & 367 & 367 \\
\hline R2 Within & 0.171 & 0.248 & 0.268 & 0.278 \\
\hline R2 Between & 0.0773 & 0.00171 & 0.129 & 0.0667 \\
\hline R2 Overall & 0.0946 & 0.000860 & 0.174 & 0.118 \\
\hline Breusch-Pagan (lm) & 70.56 & Breusch-Pa & an (p-value) & 0 \\
\hline Hausman-test (chi2) & 95.74 & Hausman- & st (p-value) & 0 \\
\hline
\end{tabular}


Table 21: Determinants of acceptance of condom use (Central Region)

I estimate a linear probability model using panel data from 1998-2008. Robust standard errors are indicated in parentheses $\left(* * * \mathrm{p}<0.01,{ }^{* *} \mathrm{p}<0.05,{ }^{*} \mathrm{p}<0.1\right)$.

\begin{tabular}{|c|c|c|c|c|}
\hline \multirow{2}{*}{ condom use w spouse } & \multicolumn{4}{|c|}{ Central } \\
\hline & (1) Random Effects & (2) Fixed Effects & (3) Time Dummy & (4) Two-Way FE \\
\hline \multicolumn{5}{|c|}{ Empowerment (personal) } \\
\hline \multirow{2}{*}{ education } & 0.007 & -0.010 & 0.002 & -0.009 \\
\hline & $(0.005)$ & $(0.016)$ & $(0.005)$ & $(0.017)$ \\
\hline \multirow[t]{2}{*}{ low earnings } & $0.063^{*}$ & 0.038 & 0.032 & 0.039 \\
\hline & $(0.037)$ & $(0.044)$ & $(0.036)$ & $(0.044)$ \\
\hline \multirow[t]{2}{*}{ medium earnings } & 0.059 & 0.026 & 0.028 & 0.027 \\
\hline & $(0.036)$ & $(0.043)$ & $(0.035)$ & $(0.043)$ \\
\hline \multirow[t]{2}{*}{ high earnings } & $0.067^{*}$ & 0.023 & 0.032 & 0.026 \\
\hline & $(0.035)$ & $(0.043)$ & $(0.034)$ & $(0.043)$ \\
\hline \multirow[t]{2}{*}{ language } & 0.011 & 0.021 & -0.009 & 0.009 \\
\hline & $(0.026)$ & $(0.055)$ & $(0.026)$ & $(0.055)$ \\
\hline \multicolumn{5}{|c|}{ Empowerment (interpersonal) } \\
\hline \multirow[t]{2}{*}{ no financial support } & $0.053^{*}$ & 0.009 & 0.036 & 0.011 \\
\hline & $(0.027)$ & $(0.033)$ & $(0.027)$ & $(0.033)$ \\
\hline \multirow[t]{2}{*}{ violence } & 0.007 & 0.016 & 0.016 & 0.022 \\
\hline & $(0.030)$ & $(0.036)$ & $(0.029)$ & $(0.035)$ \\
\hline \multirow[t]{2}{*}{ infidelity } & -0.044 & $-0.084^{* *}$ & $-0.056^{*}$ & $-0.084^{* *}$ \\
\hline & $(0.032)$ & $(0.037)$ & $(0.030)$ & $(0.037)$ \\
\hline \multirow[t]{2}{*}{ HIV infected } & 0.009 & -0.005 & 0.001 & -0.016 \\
\hline & $(0.032)$ & $(0.038)$ & $(0.032)$ & $(0.039)$ \\
\hline \multirow[t]{2}{*}{ no family planning } & $0.083^{* * *}$ & $0.056^{*}$ & $0.078 * * *$ & 0.051 \\
\hline & $(0.030)$ & $(0.033)$ & $(0.029)$ & $(0.033)$ \\
\hline \multirow[t]{2}{*}{ number of wives } & 0.023 & 0.004 & 0.017 & 0.002 \\
\hline & $(0.019)$ & $(0.022)$ & $(0.019)$ & $(0.023)$ \\
\hline \multirow[t]{2}{*}{ age at marriage } & -0.000 & 0.016 & 0.001 & 0.017 \\
\hline & $(0.003)$ & $(0.012)$ & $(0.003)$ & $(0.012)$ \\
\hline \multicolumn{5}{|c|}{ Household and background characteristics } \\
\hline \multirow[t]{2}{*}{ relative wealth } & -0.011 & -0.010 & -0.009 & -0.004 \\
\hline & $(0.015)$ & $(0.018)$ & $(0.014)$ & $(0.019)$ \\
\hline \multirow[t]{2}{*}{ children } & -0.006 & $-0.028^{*}$ & -0.009 & $-0.027^{*}$ \\
\hline & $(0.007)$ & $(0.016)$ & $(0.007)$ & $(0.016)$ \\
\hline \multirow[t]{2}{*}{ number of marriages } & 0.025 & $-0.232^{*}$ & -0.003 & $-0.223^{*}$ \\
\hline & $(0.031)$ & $(0.126)$ & $(0.030)$ & $(0.126)$ \\
\hline \multirow[t]{2}{*}{ AIDS victims } & $0.003^{*}$ & 0.003 & 0.000 & 0.002 \\
\hline & $(0.001)$ & $(0.003)$ & $(0.002)$ & $(0.003)$ \\
\hline age & 0.002 & $0.040^{* * *}$ & -0.006 & 0.039 \\
\hline & $(0.005)$ & $(0.015)$ & $(0.005)$ & $(0.026)$ \\
\hline age squared & 0.000 & -0.000 & 0.000 & -0.000 \\
\hline & $(0.000)$ & $(0.000)$ & $(0.000)$ & $(0.000)$ \\
\hline Constant & 0.053 & $-0.785^{* *}$ & $0.452^{* * *}$ & -0.890 \\
\hline & $(0.103)$ & $(0.304)$ & $(0.112)$ & $(0.835)$ \\
\hline time dummies & No & No & Yes & Yes \\
\hline Observations & 1,407 & 1,407 & 1,407 & 1,407 \\
\hline Number of respondents & 467 & 467 & 467 & 467 \\
\hline R2 Within & 0.0267 & 0.0729 & 0.0632 & 0.0776 \\
\hline R2 Between & 0.0413 & $1.26 \mathrm{e}-06$ & 0.0815 & 0.000167 \\
\hline R2 Overall & 0.0272 & 0.00247 & 0.0649 & 0.00270 \\
\hline Breusch-Pagan (lm) & 21.74 & Breusch-Pa & an (p-value) & $1.56 \mathrm{e}-06$ \\
\hline Hausman-test (chi2) & 63.76 & Hausman- & st (p-value) & $4.98 \mathrm{e}-07$ \\
\hline
\end{tabular}


Table 22: Determinants of acceptance of condom use (Northern Region)

I estimate a linear probability model using panel data from 1998-2008. Robust standard errors are indicated in parentheses $\left({ }^{* * *} \mathrm{p}<0.01,{ }^{* *} \mathrm{p}<0.05,{ }^{*} \mathrm{p}<0.1\right)$.

\begin{tabular}{|c|c|c|c|c|}
\hline \multirow{2}{*}{ condom use w spouse } & \multicolumn{4}{|c|}{ North } \\
\hline & (1) Random Effects & (2) Fixed Effects & (3) Time Dummy & (4) Two-Way FE \\
\hline \multicolumn{5}{|c|}{ Empowerment (personal) } \\
\hline education & $\begin{array}{c}0.002 \\
(0.007)\end{array}$ & $\begin{array}{c}-0.010 \\
(0.025)\end{array}$ & $\begin{array}{c}-0.001 \\
(0.006)\end{array}$ & $\begin{array}{c}-0.009 \\
(0.026)\end{array}$ \\
\hline \multirow{2}{*}{ low earnings } & $-0.081^{*}$ & $-0.137^{* *}$ & $-0.117^{* * *}$ & $-0.100^{*}$ \\
\hline & $(0.045)$ & $(0.054)$ & $(0.045)$ & $(0.055)$ \\
\hline \multirow[t]{2}{*}{ medium earnings } & -0.049 & -0.080 & $-0.082^{*}$ & -0.046 \\
\hline & $(0.048)$ & $(0.054)$ & $(0.047)$ & $(0.054)$ \\
\hline \multirow[t]{2}{*}{ high earnings } & -0.073 & -0.075 & $-0.090^{* *}$ & -0.058 \\
\hline & $(0.045)$ & $(0.053)$ & $(0.044)$ & $(0.053)$ \\
\hline \multirow[t]{2}{*}{ language } & -0.019 & -0.042 & -0.053 & -0.052 \\
\hline & $(0.042)$ & $(0.070)$ & $(0.042)$ & $(0.072)$ \\
\hline \multicolumn{5}{|c|}{ Empowerment (interpersonal) } \\
\hline no financial support & 0.017 & 0.025 & 0.030 & 0.005 \\
\hline \multirow{2}{*}{ violence } & (U.031) & (U.037) & $\begin{array}{l}(0.031) \\
0.013\end{array}$ & (U.036) \\
\hline & $(0.029)$ & $(0.035)$ & $\begin{array}{l}0.013 \\
(0.029)\end{array}$ & $(0.035)$ \\
\hline \multirow[t]{2}{*}{ infidelity } & 0.045 & 0.055 & 0.013 & 0.055 \\
\hline & $(0.028)$ & $(0.034)$ & $(0.029)$ & $(0.034)$ \\
\hline \multirow[t]{2}{*}{ HIV infected } & $0.056^{*}$ & 0.019 & 0.047 & -0.000 \\
\hline & $(0.034)$ & $(0.043)$ & $(0.035)$ & $(0.044)$ \\
\hline \multirow[t]{2}{*}{ no family planning } & 0.015 & 0.026 & 0.009 & 0.024 \\
\hline & $(0.037)$ & $(0.045)$ & $(0.037)$ & $(0.044)$ \\
\hline \multirow[t]{2}{*}{ number of wives } & $0.072^{* * *}$ & $0.063^{* * *}$ & $0.068^{* * *}$ & $0.063^{* * *}$ \\
\hline & $(0.015)$ & $(0.023)$ & $(0.015)$ & $(0.024)$ \\
\hline \multirow[t]{2}{*}{ age at marriage } & 0.002 & 0.012 & 0.004 & 0.008 \\
\hline & $(0.003)$ & $(0.012)$ & $(0.003)$ & $(0.012)$ \\
\hline \multicolumn{5}{|c|}{ Household and background characteristics } \\
\hline \multirow[t]{2}{*}{ relative wealth } & -0.003 & -0.012 & -0.000 & -0.006 \\
\hline & $(0.019)$ & $(0.024)$ & $(0.019)$ & $(0.024)$ \\
\hline \multirow[t]{2}{*}{ children } & $0.019^{* *}$ & 0.019 & $0.020^{* *}$ & 0.019 \\
\hline & $(0.009)$ & $(0.022)$ & $(0.009)$ & $(0.022)$ \\
\hline \multirow[t]{2}{*}{ number of marriages } & 0.001 & -0.063 & -0.027 & -0.014 \\
\hline & $(0.034)$ & $(0.088)$ & $(0.035)$ & $(0.085)$ \\
\hline \multirow[t]{2}{*}{ AIDS victims } & $0.003^{* *}$ & 0.001 & 0.001 & 0.002 \\
\hline & $(0.001)$ & $(0.002)$ & $(0.001)$ & $(0.002)$ \\
\hline \multirow[t]{2}{*}{ age } & 0.001 & 0.024 & -0.012 & $0.094^{* * *}$ \\
\hline & $(0.008)$ & $(0.019)$ & $(0.008)$ & $(0.029)$ \\
\hline age squared & -0.000 & -0.000 & 0.000 & -0.000 \\
\hline & $(0.000)$ & $(0.000)$ & $(0.000)$ & $(0.000)$ \\
\hline Constant & 0.167 & -0.563 & $0.626^{* * *}$ & $-3.415^{* * *}$ \\
\hline & $(0.157)$ & $(0.435)$ & $(0.181)$ & $(0.952)$ \\
\hline time dummies & No & No & Yes & Yes \\
\hline Observations & 1,319 & 1,319 & 1,319 & 1,319 \\
\hline Number of respondents & 393 & 393 & 393 & 393 \\
\hline R2 Within & 0.0283 & 0.0522 & 0.0432 & 0.0722 \\
\hline R2 Between & 0.0672 & $7.78 \mathrm{e}-05$ & 0.130 & 0.00873 \\
\hline R2 Overall & 0.0370 & 0.00278 & 0.0640 & 0.00157 \\
\hline Breusch-Pagan (lm) & 7.112 & Breusch-Pa & $\operatorname{san}(\mathrm{p}$-value) & 0.00383 \\
\hline Hausman-test (chi2) & 35.79 & Hausman- $\mathrm{t}$ & st (p-value) & 0.00752 \\
\hline
\end{tabular}


Table 23: Determinants of acceptance of condom use (Southern Region)

I estimate a linear probability model using panel data from 1998-2008. Robust standard errors are indicated in parentheses $\left({ }^{* * *} \mathrm{p}<0.01,{ }^{* *} \mathrm{p}<0.05,{ }^{*} \mathrm{p}<0.1\right)$.

\begin{tabular}{|c|c|c|c|c|}
\hline \multirow{2}{*}{ condom use w spouse } & \multicolumn{4}{|c|}{ South } \\
\hline & (1) Random Effects & (2) Fixed Effects & (3) Time Dummy & (4) Two-Way FE \\
\hline \multicolumn{5}{|c|}{ Empowerment (personal) } \\
\hline \multirow[t]{2}{*}{ education } & $0.018^{* *}$ & 0.030 & $0.014^{*}$ & 0.027 \\
\hline & $(0.007)$ & $(0.036)$ & $(0.007)$ & $(0.037)$ \\
\hline \multirow[t]{2}{*}{ low earnings } & $0.079^{*}$ & 0.071 & 0.049 & 0.063 \\
\hline & $(0.047)$ & $(0.068)$ & $(0.049)$ & $(0.068)$ \\
\hline \multirow[t]{2}{*}{ medium earnings } & 0.062 & 0.006 & 0.023 & 0.007 \\
\hline & $(0.050)$ & $(0.070)$ & $(0.051)$ & $(0.070)$ \\
\hline \multirow[t]{2}{*}{ high earnings } & $0.155^{* * *}$ & 0.067 & $0.115^{* *}$ & 0.071 \\
\hline & $(0.056)$ & $(0.075)$ & $(0.058)$ & $(0.076)$ \\
\hline \multirow[t]{2}{*}{ language } & 0.033 & -0.058 & -0.012 & -0.064 \\
\hline & $(0.048)$ & $(0.088)$ & $(0.049)$ & $(0.089)$ \\
\hline \multicolumn{5}{|c|}{ Empowerment (interpersonal) } \\
\hline \multirow{2}{*}{ no financial support } & 0.043 & -0.016 & 0.022 & -0.020 \\
\hline & $(0.035)$ & $(0.045)$ & $(0.035)$ & $(0.045)$ \\
\hline \multirow[t]{2}{*}{ violence } & 0.028 & -0.024 & 0.024 & -0.030 \\
\hline & $(0.043)$ & $(0.056)$ & $(0.042)$ & $(0.056)$ \\
\hline \multirow[t]{2}{*}{ infidelity } & -0.060 & 0.025 & $-0.087^{*}$ & 0.022 \\
\hline & $(0.046)$ & $(0.059)$ & $(0.046)$ & $(0.059)$ \\
\hline \multirow[t]{2}{*}{ HIV infected } & 0.041 & $0.090^{* *}$ & 0.046 & $0.096^{* *}$ \\
\hline & $(0.033)$ & $(0.039)$ & $(0.032)$ & $(0.039)$ \\
\hline \multirow{2}{*}{ no family planning } & $0.074^{* *}$ & $0.091^{* *}$ & $0.072 * *$ & $0.086^{* *}$ \\
\hline & $(0.033)$ & $(0.039)$ & $(0.033)$ & $(0.039)$ \\
\hline \multirow[t]{2}{*}{ number of wives } & 0.003 & -0.012 & -0.009 & -0.018 \\
\hline & $(0.027)$ & $(0.035)$ & $(0.027)$ & $(0.037)$ \\
\hline \multirow{2}{*}{ age at marriage } & $-0.006^{* *}$ & -0.014 & $-0.006^{* *}$ & -0.012 \\
\hline & $(0.003)$ & $(0.012)$ & $(0.003)$ & $(0.013)$ \\
\hline \multicolumn{5}{|c|}{ Household and background characteristics } \\
\hline \multirow{2}{*}{ relative wealth } & $-0.031^{*}$ & $-0.065^{* * *}$ & $-0.039 * *$ & $-0.067^{* * *}$ \\
\hline & $(0.016)$ & $(0.023)$ & $(0.017)$ & $(0.024)$ \\
\hline \multirow[t]{2}{*}{ children } & 0.004 & 0.001 & 0.000 & 0.002 \\
\hline & $(0.008)$ & $(0.023)$ & $(0.008)$ & $(0.023)$ \\
\hline \multirow[t]{2}{*}{ number of marriages } & $0.042^{*}$ & 0.037 & 0.026 & 0.025 \\
\hline & $(0.024)$ & $(0.078)$ & $(0.024)$ & $(0.079)$ \\
\hline \multirow[t]{2}{*}{ AIDS victims } & -0.002 & -0.006 & -0.002 & -0.005 \\
\hline & $(0.002)$ & $(0.004)$ & $(0.002)$ & $(0.004)$ \\
\hline age & 0.006 & $0.047^{*}$ & 0.001 & 0.008 \\
\hline & $(0.008)$ & $(0.026)$ & $(0.008)$ & $(0.036)$ \\
\hline age squared & -0.000 & -0.000 & -0.000 & -0.000 \\
\hline & $(0.000)$ & $(0.000)$ & $(0.000)$ & $(0.000)$ \\
\hline Constant & $0.263^{*}$ & -0.631 & $0.624^{* * *}$ & 0.908 \\
\hline & $(0.147)$ & $(0.493)$ & $(0.171)$ & $(1.092)$ \\
\hline time dummies & No & No & Yes & Yes \\
\hline Observations & 1,089 & 1,089 & 1,089 & 1,089 \\
\hline Number of respondents & 391 & 391 & 391 & 391 \\
\hline R2 Within & 0.0336 & 0.0702 & 0.0582 & 0.0745 \\
\hline R2 Between & 0.0304 & 0.000548 & 0.0475 & 0.0188 \\
\hline R2 Overall & 0.0363 & 0.00365 & 0.0527 & 0.0269 \\
\hline Breusch-Pagan (lm) & 1.880 & Breusch-Pa & $\operatorname{san}(\mathrm{p}$-value) & 0.0852 \\
\hline Hausman-test (chi2) & 45.58 & Hausman- $\mathrm{t}$ & st (p-value) & 0.000342 \\
\hline
\end{tabular}

